Portland State University

PDXScholar

2-17-1982

\title{
Developing a Test of Communicative Competence for English as a Second Language Students at the College Level
}

Kristen Kern

Portland State University

Follow this and additional works at: https://pdxscholar.library.pdx.edu/open_access_etds

Part of the Communication Commons, and the Linguistics Commons Let us know how access to this document benefits you.

\section{Recommended Citation}

Kern, Kristen, "Developing a Test of Communicative Competence for English as a Second Language Students at the College Level" (1982). Dissertations and Theses. Paper 694.

https://doi.org/10.15760/etd.694

This Thesis is brought to you for free and open access. It has been accepted for inclusion in Dissertations and Theses by an authorized administrator of PDXScholar. Please contact us if we can make this document more accessible: pdxscholar@pdx.edu. 
AN ABSTRACT OF THE THESIS OF Kristen Kern for the Master of Arts in Speech Communication presented February 17, 1982.

Title: Developing a Test of Communicative Competence for English as a Second Ianguage Students at the College Level.

APPROVED BY MEMBERS OF THE THESIS COMMTTTEE:

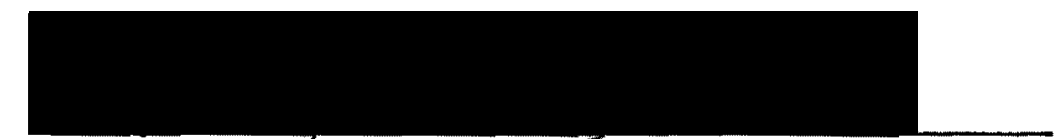

LaRay IY. Zarna, Chairman

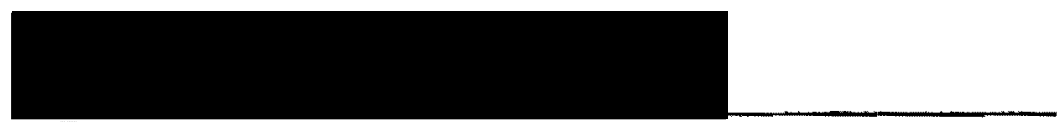

Theodore G. Grove
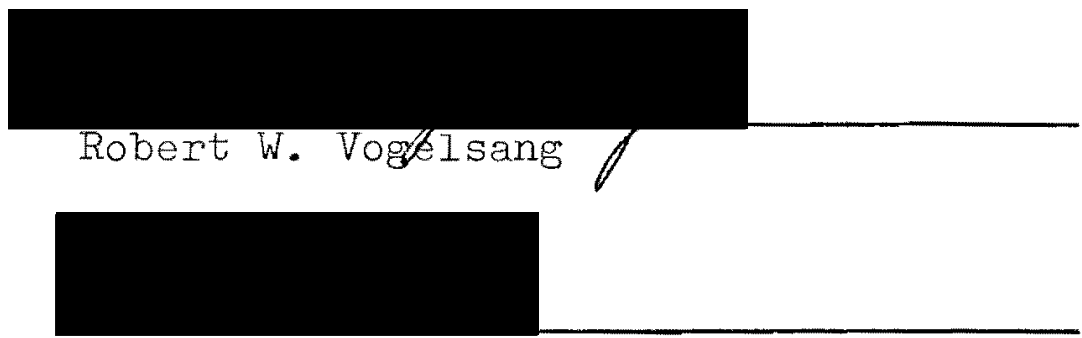

Naguib Greis

The purpose of the research was to develop a test of oral communicative competence for English as a Second Language (ESL) students at the college level.

This research first reviewed the current literature on the topic of communicative competence from the perspectives of linguistics and sociolinguistics, discourse analysis, and speech communication. The literature on testing for 
communicative competence within the ESL and foreign Ianguage teaching fields was also reviewed. A 7-minute oral semi-direct taped test was then developed and administered to a trial group of 5 ESL students and a final group of 25 ESL students at Portland State University. The test consisted of 5 short information questions and 10 social situations to which the subject was requested to respond. The test was rated for three separate criteria: intelligibility, grammatical correctness, and appropriateness. Two different raters were used for each criterion; another rater rated for all criteria. A reliability study was conducted on the raters wherein the reliability of the raters was shown to be significantly high. The validity of the test was established by conducting face-to-face interviews with the trial and final subjects prior to their taking the taped tests. The results showed that the degree of association between the overall ratings on the taped test and the overall ratings on the interview test was significant, though not significant for individual criteria. A correlation with the CELT listening comprehension test was not significant. 
DEVELOPING A TEST OF COMIUNICATIVE CONPETENCE FOR ENGLISH AS A SECOND LANGUAGE STUDENTS AT THE COLLEGE LEVEL

\author{
by \\ KRISTEN KERN
}

A thesis submitted in partial fulfillment of the requirements for the degree of

\author{
MASTER OF ARTS \\ in \\ SPEECH CONMUN ICATION
}

Portland State University

1982 
TO THE OFFICE OF GRADUATE STUDIES AND RESEARCH:

The members of the Committee approve the thesis of Kristen Kern presented February 17, 1982.

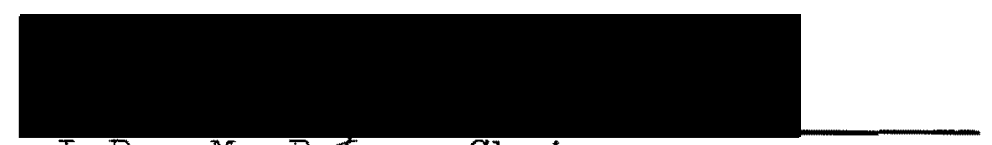

LaRay M. Bzrna, Chairman

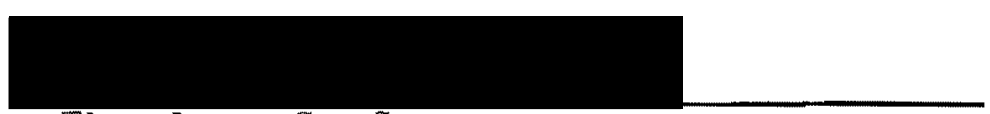

Theodore G. Grove
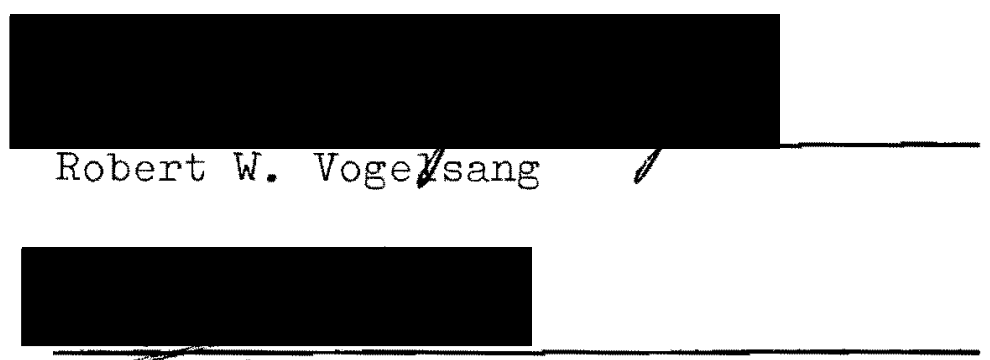

Naguib Greis

APPROVED :
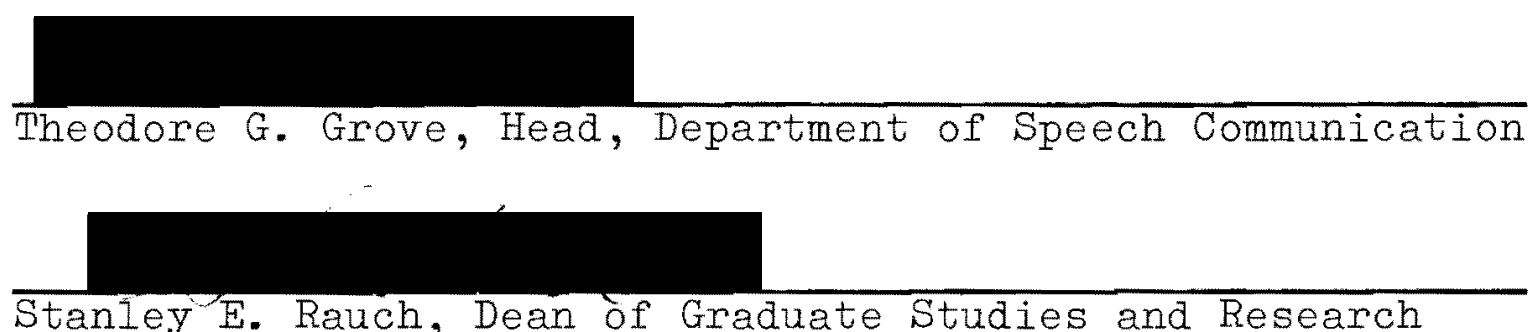


\section{ACKNOWLEDGMENTS}

A research project such as this one is not accomplished alone. Colleagues, friends, and family have all provided the inspiration, motivation, and time to see it to a close.

I would especially like to thank the members of my Graduate Committee in the Department of Speech Communication: Professor LaRay M. Barna, Dr. Theodore Grove, and Dr. Robert Vogelsang, for their knowledge, patience, and support. My graduate advisor, Professor Barna, has been a constant source of wisdom, good judgment, and interest throughout the entire thesis process.

Gratitude is also due Dr. Greis, director of the Center for English as a Second Language at PSU and Committee member, who provided the initial awareness of the need for this kind of research, and the students for its subjects.

Many thanks to those ESL student subjects who volunteered their time, and to the raters who offered theirs, to give substance to this research.

Finally, without the spiritual and physical support of family and friends, who provided assistance for nearly all aspects of this research, this challenge would never have been successfully met. To you, my thanks, love, and appreciation. 
TABLE OF CONTENTS

PAGE

ACKNOWLEDGMENTS . . . . . . . . . . . . . iii LIST OF TABLES . . . . . . . . . . . . . . vii

CHAPTER

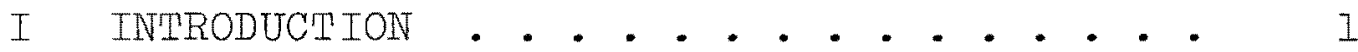

Justification ......... . 7

Purpose . . . . . . . . . . 10

II INTRODUCTION . . . . . . . . . . . . II

Iinguistic and Sociolinguistic

Perspective of Communicative

Competence . . . . . . . . .

Discourse Analysis and Communicative

Competence ......... 21

Discourse Analysis . . . . . . 27

Communicative Competence within the

Communication Field . . . . . 33

Summary . . . . . . . . . 51

III INTRODUCTION . . . . . . . . . . 53

Overview of the Research ..... . 54

Communicative Competence Criteria . . 56

Trial Interview Test and Rating . . 59

Trial Taped Test and Rating . . . . 62

Final Interviews and Ratings . . . 65 
CHAPTER

PAGE

Final Taped Test and Rating . . . . .

Reliability Study • • • • • • • . . . 71

Concurrent Validity . . . . . . . . 72

IV ANALYSIS AND DISCUSSION OF RESULTS • • • • 76

Profile of the Taped Test and

Interview Scores . . . . . . 76

Reliability Study . . . . . . . . . 78

Concurrent Valiaity . . . . . . . . 81

$V$ IMPLICATIONS FOR ENGLISH AS A SECOND

LANGUAGE • • • • • • • • • • • • • • • • •

87

Use of the Taped Test in an ESL

Program..............

87

Implications for Teaching English as a Secona Language

VI SUGGESTIONS FOR FURTHER RESEARCH AND

CONCLUDING REMARKS

Suggestions for Further Research . . . 95

Concluding Remarks . . . . . . . . 98

BIBLIOGRAPHY

99

APPENDIX

A Note to Intelligibility Raters and Rating Sheet for Intelligibility . . . . .

B Note to Grammatical Correctness Raters and Rating Sheet for Grammatical Correctness . . . . . . . . . .

C The Oral Interview of the Foreign Service Institute, Performance Factors and Rating Scale ............ . 
D Note to Appropriateness Raters and Rating sheet for Appropriateness . . . . . . . 116

E Appropriateness Rating Scale for Trial and Final Interview Test . . . . . 119

F Taped Test Script . . . . . . . . . 122 G Interaction Questionnaire . . . . . . 126 


\section{IIST OF TABLES}

TABLE

PAGE

I Trial Test Subjects - . . . . . . . . 60

I Final Test Subjects . . . . . . . . . . 67

III Profile of Scores . . . . . . . . . . 76 
CHAPTER I

\section{INTRODUCTION}

The past decade has witnessed an important shift in emphasis in the teaching of English to international students in the United States. Certainly the goal of developing a student's ability to use the language effectively for academic and social purposes has not changed over the years, yet the methods for attaining this have followed "shifts in linguistic, psychological, and pedagogical concepts which in turn cause corresponding shifts in notions of what it means to acquire, teach, or learn a language. For example, language leaming tended to mean quick and accurate translations of readings in the 1930's, but by the 50's it meant facile ability in aural comprehension and oral production" (Anthony and Norris 1972, p. 40). This audiolingual method was grounded in the theory that language is oral and that it is a system of structural contrasts. Psychologically, language was perceived as a habit to be developed and teaching techniques reflected this view.

A major innovation came when linguist Noam Chomsky theorized that as a human being learns a language, he develops the ability to generate an infinite number of grammatically correct sentences from the rules of his own 
language. Most scholars agree that this ability to use language is called grammatical or linguistic competence. Chomsky distinguished this competence from performance, or the actual use of language.

There are some who disagree with Chomsky's distinction between underlying linguistic competence and overt performance. This perspective observes that the use of language for communicating with other human beings is as important as the ability to manipulate the sounds and meanings of a language in adherence to the structure of that language. Hymes (1974) reasons:

Chomsky's interest is in moving from what is said to what is constant in grammar, and from what is social to what is innate in human nature. That, so to speak, is but half a dialectic. A thoroughgoing linguistics must move in the other direction as well, from what is potential in human nature, and in a grammar, to what is realizable and realized; and conceive of the social factors entering into realization as constitutive and rule-governed too (p. 343).

This move from a grammatical emphasis in linguistics to a communicative approach signalled an interest in the ability of language speakers to communicate according to both the grammatical and communicative rules of the language. Now the focus has become communicative competence. Hymes writes of an underlying communicative competence that enables members of a community to use and interpret the use of language (Hymes 1967, p. 17). Hymes is particularly concerned with speech when he refers to language and his term, which has been seeing more and more use, encompasses 
both linguistic and paralinguistic features in his explorations of communicative competence. This idea of communicative competence seems to have more in common with the second language teaching goal of producing a student who can communicate in the target language than the grammatical rules of Chomsky's linguistic competence, and will therefore be the basis of this research.

This need to teach communicative competence became more apparent as the English as a Second Language (ESL) student population grew in numbers and changed in points of origin. During the $70^{\prime} \mathrm{s}$, language programs were increasingly flooded with students from non-Western nations--the Middle Eastern and Asian countries especially. It became obvious to educators concerned that people do not communicate with understanding just because they speak the same language. They also must share the ability to use the communicative system as it functions within a culture. International students need to be able to "establish interpersonal contact, exchange information, reinforce the attitudes and behaviors of others, and change those attitudes and behaviors" (Book et al. 1980) to communicate effectively in a new culture with a new language.

The idea of adding communicative activities to grammar exercises has recently been advocated to develop this communicative competence. Paulston asserted: "I have come to think that it is every bit as important that we teach the 
appropriate form of social usage as the linguistic forms themselves (Paulston 1974, p. 22).

It is in the past decade that the communicative teaching approach has come into its own. Whole syllabuses, Munby's (1981) for example, have been devisea to build this communicative competence. As Iittlewood (1981) sums up:

A communicative approach opens up a wider perspective on language learning. In particular, it makes us more strongly aware that it is not enough to teach learners how to manipulate the structures of the foreign language. They must also develop strategies for relating these structures to their communicative functions in real situations and real time.

We must therefore provide learners with ample opportunities to use the language themselves for communicative purposes. We must also remember that we are ultimately concerned with developing the learners' ability to take part in the process of communicating through language, rather than with their perfect mastery in individual structures . . . . (p. $\mathrm{xi}$ ).

A considerable literature has accumulated on the teaching of communicative competence to ESI students. It stresses that the goal is to communicate appropriately, as well as grammatically correctly, with native speakers in social situations. Most of the authors are concerned with examining the sociocultural rules which govern our verbal and nonverbal code.

Although communicative competence is a new focus for the linguists, it has been the basis of the field of speech communication since its inception. Early rhetoricians expounded the "ethos," "Iogos," and "pathos" in speaking. The fundamental considerations of rhetoric are concerned 
with the total context of public speaking. Historically rhetoric concerns the good man speaking well. The effectiveness of a speech depends upon the relationship that exists between the speaker and the audience as well as the topic of the speech. "Analyze your audience" and "adapt to your audience" are the first rules of rhetoric. The speaker must be aware of the audience's background, knowIedge, and attitudes towards the speaker's purpose, what the speaker wants believed, to be most persuasive. The speaker, also realizing that people are persuaded by other people and not necessarily by information, should investigate how the audience perceives him or her, whether they will accept and believe what is said because she or he is delivering the information. When preparing a speech, the speaker should work toward an organization and style that will make the speech clear and appropriate for the audience. Lastly the speaker needs to consider the verbal and nonverbal aspects of delivery--the speaker's appearance, demeanor, vocalization, and behavior. There is thus a historical background in the speech communication field on how a person commicates effectively and persuasively that is particularly germane to a comprehensive investigation of the notion of communicative competence.

It is interesting to note that speech communication started using the term competence at the same time as the linguists. For example, Wiemann (1977) defined the term as: 
- . the ability of an interactant to choose among available communicative behaviors in order that he may successfully accomplish his own interpersonal goals during an encounter while maintaining the face and line of his fellow interactants within the constraints of the situation ( $p .198$ ).

Three schools of thought, namely the self-presentation approach (Goffman 1959), the T-group approach (Bochner and Kelly 1974), and the social skill approach (Argyle 1969), reported specific behaviors related to dimensions of a communicative competence model which Wiemann (1977) promulgated. Further, Wiemann and Backlund (1980) in a recent review have identified three primary dimensions of communicative competence as empathy, behavioral flexibility, and interaction management.

It is worthwhile sharing perspectives across disciplines. Speech communication has enlarged its scope in the last fifteen years to include the area of intercultural communication. This field has much to add to the linguistic perspective of communicative competence with regard to the theory and research developed here on international students. For example, both Barna's discussion on stumbling blocks in interpersonal intercultural communication (1972) and Kim's work on acculturation (1977) point to other nonlinguistic variables which affect the intercultural communication process. The continuing examination of communicative competence by the communication and intercultural communication fields and linguistic field is important. Each can help the other. A truly thorough view of the 
concept for international students should keep in mind those behavioral, cultural, and intercultural factors that influence communication in addition to the strictly languagerelated social factors. And likewise speech communication can benefit from information on the matter of language.

\section{JUST IFICATION}

Always accompanying language teaching is testing. Testing is primarily used for two purposes. The first is to determine what a student has achieved through the learning process. The second reason is to assess how proficient a student is at one or more skills. This type of evaluation is often used to place a student at the appropriate level of a language program. Standardized proficiency tests of vocabulary, grammar, reading, and listening comprehension exist to evaluate these skill areas, but oral communication assessment of second language leamers has thus far eluded large scale test making and evaluation. There is no standardized testing method where a student responds orally to stimuli either live or on a recording tape. The one exception to this is the TOEFI Speaking Test, optional since 1979, offered by the Educational Testing Service (ETS). This instrument includes several communicative test item types: telephone conversations and social situations. There are other vocal tests, however. Some are used to assess features of oral production, sound discrimination 
for example, or grammar. They are, in other words, concerned with evaluating linguistic competence rather than communicative competence. The oral interview test must also be mentioned. Most notable of this type is the Foreign Service Institute (FSI) Oral Interview. The "test" here is a conversation between examiner and examinee, often with another evaluator-observer present. Pronunciation, fluency, grammar, and vocabulary ratings are made on the examinee's performance. This interview has been found a reliable, face-valid measure of language ability, especially when evaluation standards are rigorously monitored for consistency. It is just this attention to exact standards of assessment which make it difficult for many ESL programs to implement it. Time must be spent in training, and maintaining, an examiner's judgment and sufficient time must also be allocated to individually interview each student in the language program.

It has generally been the task then of individual ESL centers to develop their own methods of assessing students' speaking ability to complement the incorporation of communication activities in the classroom. With this intent, Portland State University's Center for English as a Second Language under the direction of Dr. Naguib Greis, began a program in 1975 of what can be classified as indirect, as opposed to direct or face-to-face oral testing. This was accomplished by taping questions and social contexts 
for the students to respond to on tape, and asking them to read a short passage aloud on the tape. The tapes were then rated by a native speaker in a maimentary fashion. The question of whether or not this kind of testing empirically indicated a student's oral communicative competence is still to be addressed.

Again, while communicative activities and syllabuses are commonly used in ESL programs, testing for communicative competence is still in its infancy. There is still the feeling, as Briere (1980) states, that

On the surface, then, the answer to the question of whether we can test communicative competence would seem to be "No, we are not ready yet." However, I personally feel that, in spite of the many problems, we can test some aspects of communicative competence now. . .

- . but that it is going to take a tremendous amount of interdisciplinary research before we can really develop sophisticated testing techniques to evaluate the various levels of communicative competence of $\mathrm{I} 2$ learners/speakers in a wide variety of contexts ( $\mathrm{p} .93$ ).

In the communication field, Wiemann and Backlund (1980) close their analysis of current communicative competence research by stating, "we are not at a point of concluding, but at a point of beginning." Hwang, Chase, and Kelly (1980) also acknowledge that from the intercultural communication standpoint, "much more intercultural information (on culture specific and universal competence components) is required if we are to approach a general theory of interpersonal competence that can instruct us in our differences while encouraging us in our many similarities" ( .77$)$. 
A stated call for empirical research on communicative competence itself and to develop ways to test ESL students for communicative competence has thus been issued from three areas, speech communication, intercultural communication, and ESL, that are inherently concerned with successful human encounters.

\section{PURPOSE}

The major purpose of this study is to develop a test of oral communicative competence for ESI students.

First there will be a review of the recent literature which relates to the concept of communicative competence with concentration on the testing aspect. A test will then be constructed and tested for reliability and validity. The research methodology, analysis, and discussion of test results, implications for ESL, and concluding remarks will follow. 


\section{CHAPTER II}

\section{INTRODUCTION}

In this chapter the literature on communicative competence and communicative competence testing will be reviewed. Examination of both theory and research on this topic reveals three areas in which communicative competence has become a focus of study. First, linguistics and its subfield, sociolinguistics, which looks at language as a social phenomenon, have analyzed the notion of a competent communicator within the structure of societal norms. Second, discourse analysis which seeks to discover the rules of language use in social interactions may help to aid those who need to learn how to be communicatively competent as they move from one culture to another. Third, the communication field has directed important research toward the investigation of behavioral components of communicative competence. It is hoped that this review may help to clarify this concept.

The last section of the chapter is devoted to reviewing the state of communicative competence testing. Oral testing from a college level, foreign language, and second language viewpoint will primarily be examined. This reflects the major purpose of this thesis which is to 
develop a test of oral communicative competence for English as a Second Language students at the college level.

\section{IINGUISTIC AND SOCIOLINGUISTIC PERSPECTIVE OF COMMUNICATIVE COMPETENCE}

Noam Chomsky's discussions of language acquisition signalled a new theoretical direction in linguistics. Turning from descriptions of language structures as being habit-formed patterns, he developed the theory that language is a rule-governed phenomenon, a "certain pairing of sound and meaning" (Chomsky 1972, p. 116), wherein the rules of syntax mediate the relation of semantic (meaning) and phonetic (sound) interpretations. An important aspect of his theory was, as mentioned previously, his distinction between the underlying competence and overt performance of the language speaker/hearer. Chomsky (1972) defines competence as "the ability of the idealized speaker/hearer to associate sounds and meanings strictly in accordance with the rules of his language" (p. 116). Performance he refers to as the actual observed use of language and he believes it involves many other factors in addition to competence. He explains this as follows:

We do not interpret what is said in our presence simply by application of the linguistic principles that determine the phonetic and semantic properties of an utterance. Extralinguistic beliefs concerning the speaker and the situation play a fundamental role in determining how speech is produced, identified, and understood (Chomsky 1972, p. 116). 
Because Chomsky's work is primarily concerned with the grammar, i.e., system of rules, of a language which serves as his model for idealized competence, and not performance factors, his adherents for the most part did not consider the larger view. The problem which arises from this approach is succinctly put by linguist Baker (1977) who says:

Rather than viewing language as an object with independent existence, a thing to be described for its own sake, it is evident that it must be seen as a tool, a means to an end outside itself. That end, of course, is communication, and it is only in the context of the communicative situation that the essential properties of a linguistic system can be discovered and analyzed (p. 2 ).

This is another way of expressing the idea that to talk of language without, at the same time, accounting for its social, human characteristics is "but half a dialectic" (Hymes 1974, p. 343).

Disciplines which have contributed to the literature on aspects of language use in society include sociology, anthropology, and especially the comparatively recent subfield of sociolinguistics. Sociolinguistics has developed into a formal discipline which "seeks to discover the societal rules or norms that explain and constrain language behavior and the behavior toward language in speech communities" (Fishman 1972, p. 3). It is not the purpose of this discussion to thoroughly explore this field, but to mention that sociolinguistics has contributed to a conception of communicative competence. Fishman (1972) suggests that the field 
may help in the understanding of communicative competence as a basic aspect of man's social nature. He defines communicative competence as "the rules that native members of speech communities implicitly grasp and that constitute their sociolinguistic behavior" (p. 16).

Dell Hymes, the best known anthropologist/sociolinguist concerned with communicative competence detailed a construct for analyzing speech using the acronym SPEAKING: S--Setting or Scene; P--Participants or Personnel; E--Ends (goals and outcomes); A--Art characteristics, form and content; K--Key (the tone, manner or spirit in which an act is done, which may be nonverbal); I--Instrumentalities, channel, and code; N-Norms of interaction and interpretation; G-Genres, categories of types of speech acts and events. He was interested in discovering the native system and theory of speaking. He believes this study will cnable one to describe communicative competence:

- . that [which] enables a member of the community to know when to speak and when to remain silent, which code to use, when, where and to whom, etc., - . the knowledge, sometimes conscious, sometimes unconscious that enables persons to use language in social life. . . the underlying communicative competence that enables members of a community to use and interpret the use of language (Hymos 1967, pp. 13-17).

The last statement is significant in that Hymes has here used the term "underlying" in connection with communicative competence. Several years later he explained his conceptions of competence and performance more fully. He first observed that a normal member of a speech community 
has both the knowledge of and a capability with regard to each of four aspects of the communicative system available to him or her. Those four sectors of his communicative competence reflect the speaker-hearer's grammatical (formally possible), psycholinguistic (implementationally feasible), sociocultural (contextually appropriate), and de facto (actually occurring) knowledge and ability for use (Murby 1981, p. 14).

Hymes (1972) defines his conception of the words competence, knowledge, and ability for use as:

I should take competence as the most general term for the capabilities of a person. . . Competence is dependent upon both (tacit) knowledge and (ability for) use. Knowledge is distinct, then, both from competence (as its part) and from systemic possibility (to which its relation is an empirical matter).

- . knowledge also is to be understood as subtending all four parameters of communication just noted. There is knowledge of each. Ability for use also may relate to all four parameters. Certainly it may be the case that individuals differ with regard to ability to use knowledge of each: to interpret, differentiate, etc. The specification of ability for use as part of competence allows for role of noncognitive factors, such as motivation, as partly determining competence ( $\mathrm{p} .282$ ).

He underscores that performance refers to actual use and actual events, with certain reminders and provisos, by saying:

- . the performance of a person is not identical with a behavioural record, or with the imperfect or partial realization of individual competence. It takes into account the interaction between competence (knowledge, ability for use), the competence of others, and the cybernetic and emergent properties of events themselves. 
In sum, the goal of a broad theory of competence can be said to be to show the ways in which the systematically possible, the feasible, and the appropriate are linked to produce and interpret actually occurring cultural behaviour (Hymes 1972, p. 283).

Other anthropologists and sociolinguists echo Hymes in their own work. Bauman (1977), in a discussion of linguistios and anthropology focusing on folklore, writes of communicative competence as "the knowledge and ability to speak in social appropriate ways; this is not simply a matter of using correct grammar but of operating appropriately within a community's system of norms of interaction and interpretation" (p. 24).

Gumperz (1975) discusses more fully the components of the rules of speaking that are becoming evident as more descriptions of speaking in culturally specific settings are available. These rules involve a complex set of factors, including choice of pronunciation and grammar, intonation and speech rhythm, discourse structures, as well as constraints on social roles enacted by speakers and listeners, and constraints on setting. He reasons that there is a structure which functions at the level of discourse which is analytically different from the grammar of individual sentences. "Communicative competence, that is, the ability to speak appropriately, implies a knowledge both of grammar and of the rules of language usage" (p. xv). 
Ervin-Tripp (1979), reviewing the speaking competence of children and systematic language variation remarks that "competence in speaking includes the ability to use appropriate speech for the circumstance and when deviating from what is normal to convey what is intended" (p. 27). Canale and Swain (1979) in their extensive work, Communicative Approaches in Second Language Teaching and Testing, use the term communicative competence to refer to "the relationship and interaction between grammatical competence, or knowledge of the rules of grammar, and socioIinguistic competence, or knowledge of the rules of language use" (p. 916). This use, along with that of Hymes, is distinguished from communicative performance, or the actualization and interaction of these two competencies in the production and comprehension of utterances under general psychological constraints unique to performance.

Beyond these definitions, Canale and Swain (1979) make four points that clarify and separate their perspectives from Hymes. First, they do not assume that communicative competence is the "highest or broadest level of language competence that can be distinguished or that is relevant for second language teaching purposes" (p. 10). In their discussion communicative competence is seen as a subcomponent of a more general language competence, and communicative performance is viewed as one form of more general language performance. Secondly, they hesitate to 
include the notion of ability for use (Hymes 1972) in their definition of communicative competence because it has not been researched thoroughly and they doubt its relevance to communicative syllabus design. They are concerned about the issue of linguistic deficit, "i.e., inadequate language competence resulting in social class and power differences" (Canale and Swain 1979, p. 18).

Their third notion is that general psycholinguistic factors such as memory and perceptual strategies belong with communicative performance rather than with communicative competence (corresponding with Hymes placement) since they assume these factors to be nonspecific to communicative competence. Finally, while communicative competence study focuses on the "relationships and interaction between regularities in grammatical competence and regularities in sociolinguistic competence" (. 19), there are aspects of each kind of competence which can be investigated on their own.

Canale and Swain (1979) also divide their concept of communicative competence into three competence areas: grammatical, sociolinguistic, and strategic. They use grammatical competence to refer to the "knowledge of lexical items and rules or morphology, syntax, sentence-grammar semantics, and phonology" ( .62$)$. They believe sociolinguistic competence to be composed of two sets of rules: sociocultural rules of use and rules of discourse. 
Sociocultural rules will indicate the ways that utterances are produced and comprehended appropriately with respect to the elements of communicative events described by Hymes. The main focus of these rules is

- . on the extent to which certain propositions and communicative functions are appropriate with a given sociocultural context depending on contextual factors such as topic, role of participants, setting, and norms of interaction. A secondary concern of such rules is the extent to which appropriate attitude and register or style are conveyed by a particular grammatical form within a given sociocultural context (Canale and Swain $1979, \mathrm{p} .62$ ).

Describing the focus of rules of discourse, Canale and Swain (1979) state that it is the "combination or utterances and communicative functions and not the grammatical wellformedness of a single utterance nor the sociocultural appropriateness of a set of propositions and communicative functions in a given context" ( .63$)$. (See the following section of this chapter for a discussion of discourse and its analysis.)

Almost unique to Canale and Swain is the third area of competence they explore: strategic competence. It seems germane when considered in light of their purpose which is to consider teaching and testing in terms of communicative approaches. Strategic competence includes both verbal and nonverbal communication devices which can be called upon to compensate for breakdowns in communication because of performance "variables" or to inadequate competence. There are two primary kinds of strategies: 
those that mainly have to do with grammatical competence and those which are concerned more with sociolinguistic. competence. As an example of the first type, the scholars offer that of an ability to paraphrase grammatical forms that one has not learned or cannot remember momentarily. An example of sociolinguistic strategy might be role-playing as in how to address strangers when uncertain of their social status.

Another scholar who has investigated the issue of competence from the perspective of rhetoric and discourse analysis is Widdowson (1971, 1975). For him communicative competence is knowing the rules of use in particular social situations and includes the knowledge of how to recognize and use sentences to perform what he refers to as rhetorical acts--e.g., defining, classifying, warning, etc. He differentiates communicative competence from grammatical competence, or rules of grammar, as does Canale and Swain. He considers that for students outside the European cultural tradition such rules of use need to be carefully taught, an important concern to English as a Second Ianguage teachers (Munby 1981, p. 18). This leads to the conclusion that these rules need to be described, as in the current work of Searle (1969).

In this section of the discussion on communicative competence, there has been a progression from the rulegoverned nature of language beginning with Chomsky to 
those who have developed the social, communicative, characteristics of the competence and performance aspects of speech within the cultural context. A broader perspective outlined by Hymes, and more specifically detailed by Gumperz, and the somewhat limiting view of Canale and Swain has been presented. The latter authors have discussed a new aspect of competence, strategic competence, in addition to the more familiar grammatical and sociolinguistic aspects. Finally the examination has reached the issue of how the analysis of language rules of use from Widaowson, Canale and Swain, Gumperz and others enters into the description of communicative competence.

\section{DISCOURSE ANALYSIS AND COMTUNICATIVE COMPETENCE}

Before tuming to the next section of this chapter which will consist of the communication field's perspective on communicative competence, it may be useful to consider the ways in which the rules for the use of language have begun to be analyzed. Interestingly, both linguists and communication scholars alike have found the analysis of talk, known variously as discourse analysis or conversational analysis, to be instrumental in furthering their research on the aynamics of humar spoken interaction.

In summarizing the theoretical framework for his communicative syllabus design model, Munby (1981) affirms that 
communicative competence involves using linguistic forms to carry out communicative acts and to comprehend the communcative functions of sentences and their relationships to other sentences ( $p$. 26). This occurs at the level of discourse which Sinclair et al. (1972) propose as that level between grammar and nonlinguistic organization (Munby 1981, p. 25). Included in this view of communicative competence is the knowledge of the rules of use that control the patterning of such acts, the interpretive strategies of the language user, and the contextual meaning of an utterance (the basic structural unit of talk) (Iitton-Hawes 1977 , p. 4). The units of discourse have features and "formal rules of occurrence" that can be defined (Munby 1981, p. 26).

These parameters of communicative competence at the level of discourse relate to what the linguist Gumperz (1977) calls conversational inference. By this he means that a speaker is "able to produce an appropriate response, that is, following lines of thematic progression which take the form of linguistically and culturally sanctioned relationships between utterances" ( $p$. 194). This process involves first the perception of "contextualization cues" which can be any aspect of the surface form of utterances that are significant in the signalling of interpretative frames. These cues are usually prosodic and paralinguistic, but can include lexical and phonological alternates, 
employment of idiomatic sequences or set formulas, or codeswitching (p. 199). These cues are, moreover, uninterpretable apart from concrete situations which Gumperz (1977) calls "speech activities" ( $\mathrm{p}$. 205). Giving "discussing politics," "chatting about the weather," and "lecturing about linguistics," as examples, he admits that while they are not precisely named, they are the means through which social knowledge is preserved in the form of limits on action and possible interpretation (p. 206).

Second, there is the interpretation of these contextualization cues. This involves the contextualization process in which message meaning and sequencing patterns are evaluated in relation to the contextualization cues. The association exists in "co-occurrence expectations" that are leamed through interactive experience and form part of our habitual and instinctive linguistic knowledge. They permit us to match styles of speaking with contextual assumptions, and are, Gumperz (1977) states, "highly culturally specific" (p. 199).

Thus, according to Gumperz, discourse involves perceiving and interpreting culturally, contextually significant cues and the analysis, therefore, would need to consider not only the surface meaning of utterances, but the total communication milieu. For example, on the basis of previous nonverbal behavior research, Gumperz (1977) points out that the maintenance of successful conversation is 
crucially dependent on the speakers "and listeners" abilities to establish a rhythmic interchange of speakership and listenership signals through verbal actions such as gaze direction, posture, head nods, eye blinks, and so on (p. 206 ). Jakobovits (1974), a psycholinguist, based his discussion on the analysis of conversation and the theory of communicative competence on ethnomethodological precepts (Garfinkel 1968). He defines ethnomethodology as the study of the transactional practices of individuals when they are being ordinary (Jakobovits 1974, p. 231). His point is that ordinary interaction becomes the substance from which discoveries can be made about communicative competence. Discussing the nature of concepts in a theory of communicative competence, he makes four observations. The first is that the analysis of the meaning of an utterance must take into account the contextual background structure of the conversational circumstance in which it is embedded. Second, there must be some specific working concepts that have the character of being "operative" acts, by which he means that it is the doing of them that forms what it is that they are. Third, the likely meaning of an utterance has to be explained within a structure that perceives an utterance as a sequential step within a greater interactional sequence that has the nature of a "co-occurrent oriented to work" by two or more participants. Here he clarifies that relevant data for analyzing social 
interactions are those features that by presence or absence are noticed or given overt interpretive significance. He says: "Most people spend most of their time being ordinary; they are masters at it; it means being socialized; it means having communicative competence" (Jakobovits 1974, p. 237). Jakobovits last observation is that the analysis of conversational interactions have to be made in the form of "prescriptive rules" wherein each event in the conversation either adheres to a prescribed rule or violates it. This is to say that conversational analysis should not be descriptively neutral. He then continues, defining communicative competence in terms of the participant's knowledge of the subcultural rules of conversational interaction. To describe this knowledge requires a syntactic analysis of the conversational events and a semantic analysis of speech acts $(p \cdot 244)$.

Jakobovits (1974), then, does not greatly differ from Gumperz and others in his recognition of the sequential nature of talk, its rule-governed nature, and the importance of contextual structure to conversation. Also his conception of communicative competence as the knowing of subcultural rules of conversational interaction, acquired in the context of socialization ( $\mathrm{p} \cdot 244)$, is complementary with those views given previously. It should be mentioned that Jakobovits separates linguistic (grammatical) competence from social interactional and communicative 
competence (p. 244). In doing so he follows the linguists and sociolinguists. Elsewhere Jakobovits uses the term "transactional competence" because he felt that "talk (the use of language) is much more than communication (transmitting messages) . . It is a transaction, it is doing something together" (pp. 136, 137). This highlights the difference bètween the approach of a representative linguist and the scholar in the field of speech communication who would include talk, the use of language, as part of the total communication process. It appears that they conceptually agree but are using different terminology.

Jakobovits had referred to the literature on discourse analysis, as have scholars in the communication field. Just recently interest in the analysis of conversation has grown in the communication discipline as well (Litton-Hawes 1977; Nofsinger 1977; Jurick 1977). Coming from the "naturalistic" perspective of communication studies, Nofsinger (1977) states that: "communication is worth studying in itself rather than as an indicator of something else, such as attitudes, cognitive balance mechanisms, group cohesiveness, or communication apprehension" (p. 12). He also believes:

- - society is not seen as a function of certain superordinate and determining variables such as source credibility, ego involvement, persuasibility, or socio-economic class, but rather is seen as built up or created by the interactions of people going about their everyday lives (p. 12). 
DISCOURSE ANALYSIS

The discussion which follows first briefly defines discourse analysis and then presents two paradigms for analyzing everyday communication from the viewpoint of communication scholars. From this perspective, the study of everyday talk concentrates on the ways that language is used for communication (pragmatics) rather than on its syntactic or semantic correctness. This emphasis does not deny the necessary knowledge of syntax or semantics, but considers it an insufficient condition for people to converse (Litton-Hawes 1977, p. 3).

Discourse analysis is one method used to identify rules of language use in social interaction. Here discourse refers to a written transcription of talk. A rule is an attempt to demonstrate how one behavior (or utterance, the basic structural unit of talk) follows another and how the members who perform that behavior understand it (Litton-Hawes 1977, p. 4). Litton-Hawes characterized rules in three ways. First, they are formal descriptions of the operations performed by speakers when talking. Second, rules carry out a categorizing role defining or accounting for what comprises a speech act (promise, question, assertion, or other). Third, rules must indicate the conditions under which the categorized act operates, since the same speech patterns undertake different functions at different times (p. 6). 
One paradigm built on this rule-defining method is that proposed by Frentz and Farrell (1976) from which Nofsinger (1977) borrowed. Called the "language-action" paradigm, it is constituted of three parts--context, episodes, and symbolic acts. The most general component, context, is defined as that which "specifies the criteria for interpreting both the meaningfulness and propriety of any communicative event" (Frentz and Farrell 1976, p. 334). Context, in communication, is recognized on two hierarchical levels namely form of life and encounters. The first level, forms of life, are, according to Toulmin (1969) ". . those partially linguistic and partially nonlinguistic constellations of activities which fix the meanings of concepts and expressions" (pp. 73-74). Frentz and Farrel1 (1976) also point out that form of life

- . is a kind of knowledge which communicators share through language... imposes upon communication an aesthetic pattern which triggers actor expectation . . and exerts indirect social regulation (institutions) upon communicative events (p. 334).

They state the second level of context is encounters, which "articularize form of life through rules of propriety" (p. 334). It is the concrete dimension of context that actualizes form of life in terms of the here and now. Encounters are the practical means to fulfill expectations of form, and it is their institutional restraint which determines the propriety of communicative choices. 
In the view of Frentz and Farrel1 (1976), the basis for comprehending a communication act is the episode. "An episode is a rule-conforming sequence of symbolic acts (see below) generated by two or more actors who are collectively oriented toward emergent goals" (p. 336). With regards to rules, episodes are rule-conforming to the degree that actors take on responsibility for free choice within any episode. For an episode to develop, the communicators must agree, at least tacitly, upon the congruity of aims they are pursuing. The principal characteristic of episodes is that "episodic form defines the structure of communication" (p. 338). This form does not consist of surface stylistic variations, but of a recurrent analytic base composed of a series of "structural imperatives" having to do with (1) acknowledging the presence of others and being willing to communicate, (2) defining the kind of episode being enacted, (3) confirming the rules of propriety, (4) developing strategies towards mutually acceptable goals, involving the knowledge of both actual and potential choices, and (5) termination of the episode (pp. 338-340).

Symbolic acts function importantly in the development of episodic structure. They are, in the words of Frentz and Farrell (1976), "verbal and/or nonverbal utterances which express intentionality" (p. 340). Three properties clarify the recognizable features of symbolic acts. These are propositional force, approximately formal semantic 
meaning; expressive force, the asituational function that each act performs such as promising, threatening, etc.; and consequential force, the effect the act has upon another actor $(\mathrm{p} \cdot 340)$.

Frentz and Farrell add another feature of symbolic acts: episodic force. They explain that the Speech Act vocabulary of Searle (1969) and others is insufficient to describe communication, though the features given thus far could be construed as the same as their locutionary (semantic), perlocutionary (consequential), and ilocutionary (functional) forces. They state that the additional force is that which specifies "the communicative function of acts within the overall sequential structure of an episode . . ." (p. 340$)$.

According to Frentz and Farrell (1976) the effect that verbal and/or nonverbal utterances have on another actor follow logically from this communicative function of the utterances. In situations where the communicative function (episodic force) of the utterances within the episode is identical to the function the act performs (expressive force) such as promising, flattering, or requestion, then the effect of the utterance can be directly inferred. However, if the communicative function and the expressive force are different, the effect the act has on another actor (consequential force) and the expressive force implicitly identify the episodic force of the act. For 
example, "Could I have a drink of water?" followed by "Mark, it's bedtime" seem unrelated until analyzed. The encounter-context is a father and son at the son's bedtime. While the expressive force of the request is clear, the consequential force results in a failure to acknowledge the request. In a larger context, though, the episodic force of the request is known by the father as a tactic used to forestall going to bed, and therefore his reply is logical in terms of the rules in this encounter type. While not specifically related to a description of communicative competence, it may be that this three-part paradigm of Frentz and Farrell--context, episode, and symbolic acts-can offer a concrete way of determing Gumperz' "appropriateness" and Jakobovits" "ordinariness."

The analysis of discourse has likewise been applied in the area of intercultural communication. Schneider (1980), referring to the process of acculturation and the ways of assessing its progress, states: "What is needed - - are direct measures of immigrants changing communicative competence and performance which can be assessed in relationship to ultimate success and ability to function in the new culture" (p. 3). Schneider continues by discussing various indices of verbal and nonverbal communication behavior which help to provide understanding of the acculturation of Chinese immigrants in the United States. He focuses on the use of language in everyday discourse. 
For this he employs a model of pragmatic communication comprised of four levels of analysis necessary to understand intercultural discouse: (1) the speech act level in which a verbal or nonverbal action is interpreted in terms of "what an utterance 'means' in a semantic sense but also what it does in the context of a communication situation; (2) the ritual level of conversation where a sequence of speech acts has a definite, culturally determined meaning; (3) the strategic level of interaction where strategies consist of combinations of intentions, situations and messages in conversational discourse; and (4) the organizational level of conversational discourse" (Schneider 1980, pp. 5-10). Schneider agrees with Sanders (1979) who argued convincingly that in order for conversations to be coherent they must be governed by underlying logical mules. Though these rules are not detailed here, it seems clear that there is interest from many fields in articulating them. Necessary features and paradigms have been set forth to extract rules of language use. Accepted components include context, meaning and interpretation of spoken and nonverbal acts, the importance of sequence in speech events (episodes), and the influence of culture on communicative acts. The last is especially noteworthy for intercultural research. Both Gumperz (1977) and Schneider (1980) point out that the interpretation of "contextualization cues" (Gumperz, p. 199) and comprehension of strategic interaction (Schneider, p. 9) are very probably culturally determined. 
COMMUNICATIVE COMPETENCE WITHIN THE COMNUNICATION FIELD

The final perspective which needs to be explored for its contributions to the study of communicative competence is that of speech communication. Over the last 25 years there has been much research done on human communication and the factors which affect it. Watzlawick, Beavin, and Jackson (1967), perceive communication as behavior and do not consider it in terms of a "monophonic message unit, but rather with a fluid and multifaceted compound of many behavioral modes-verbal, tonal, postural, contextual, etc.--all of which qualify the meaning of all the others" (p. 50).

A principal researcher of communicative competence from the speech communication perspective, John Wiemann (1977), traces his approach to three main schools of thought. These are the $\mathrm{T}$-group, self-presentation, and social skill approaches. When he designed his model of communicative competence, Wiemann pulled from all of these areas to fill out his model with behavioral cues in five dimensions: affiliation/support, social relaxation, empathy, behavioral flexibility, and interaction management. For all of these dimensions both verbal and nonverbal behaviors are included. The last dimension, interaction management, is given as the "sine qua non of competence" (p. 199). It was found through his research to be the determining 
aspect of the model. "Even relatively small changes in management behavior resulted in large variations in evaluations of communicative competence" (italics Wiemann's 1977 , p. 210).

The two critical interaction management skills for competence are given by Argyle (1969): "(1) the ability to establish and sustain a smooth and easy pattern of interaction and (2) the ability to maintain control of the interaction without dominating--responding in accordance with an internal plan, rather than simply reacting to the other's behavior" (pp. 327-328). Wiemann (1977) notes that the first skill is "dependent on the rule-governed nature of face-to-face encounters. It is the adherence or nonadherence to these culturally sanctioned rules which behaviorally define this dimension of communicative competence" (p. 199). Five pertinent rules to communicative competence are then listed, and sources given (in the original). They are as follows:

(1) Interruptions of the speaker are not premitted.

(2) One person talks at a time.

(3) Speaker turns must interchange. (Subject to different interpretations.)

(4) Frequent and lengthy pauses should be avoided.

(5) An interactant must be perceived as devoting full attention to the encounter.

The second interaction management skill can be explained 
behaviorally as "the topic control exercised by an interactant" (Wiemann 1977, p. 199).

Wiemann (1977) sums up the importance of the interaction management aspect to communicative competence this way:

Interaction management is concerned with the "procedural aspects that structure and maintain an interaction. These include initiation and termination of the encounter, the allocation of speaking turns, and control of topics discussed. Skiliful interaction management is defined as the ability to handle these procedural matters in a manner that is mutually satisfactory to all participants. . . " It is the mastery of these skills which permits a person to implement (or conform to) the interaction rules of his culture (p. 199).

More recently, Wiemann and Backlund (1980) reviewed the communicative competence literature focusing on its relevance to the education field. Here they described empathy as the "most clearly crucial aspect of communicative competence" (p. 194). This includes affiliation and support. This finding is supported by the intercultural research carried out by Hwang, Chase, and Kelly (1980). Interaction management and behavioral flexibility (adaption) also emerge as key dimensions of communicative competence from this review of the literature.

These dimensions point out that the communicative competence perceived here is more than one tied to language usage alone. Wiemann and Backlund (1980) recall Wiemann's definition of the concept: 
Communicative competence is the ability of an interactant to choose among available communicative behaviors in order that he (she) may successfully accomplish his (her) own interpersonal goals during an encounter while maintaining the face and line of his (her) fellow interactants within the constraints of the situation (Wiemann 1977, p. 198).

It is incumbent here to briefly define the terms "face" and "Iine" that Wiemann has incorporated in his definition of communicative competence. These two words as Goffman (1974) described them:

- . in social encounters, a person tends to act out . . a line--that is, a pattern of verbal and nonverbal acts by which he expresses his view of the situation and through this his evaluation of the participants, especially himself . . . the term face may be defined as the positive social value a person effectively claims for himself by the line others assume he has taken during a particular contact (p. 224).

It can be seen, then, that there is reference to this idea of communicative competence in several disciplines interested in human, social behavior. The work to definitely describe the parameters of this competence is far from finished. Especially as more intercultural research is undertaken it is important, as Schneider (1980) states, to "recognize underlying processes of the cross-cultural acquisition of communicative behavior which may reflect universals of communication" (p. 3).

\section{TESTING FOR COMMUNICATIVE COMPETENCE}

Since, as the preceding review has shown, communicative competence is a fairly recent concept, the testing for 
it is understandably in an immature stage as well. This section will trace the testing developments within the foreign and second language teaching-testing domains. The background necessary for formulating an oral test of communicative competence suitable for college level ES.L students will be found here.

Generally, a test examines that which is considered important for the examinee to know. It is not surprising, then, that as the language teaching classrooms have, until recently, stressed knowledge of grammar, so the tests in language classes tended to be tests of grammar. There has been a movement in the field to change this direction in instruction. It is exciting to develop communicative activities that enable a student to use a language in meaningful contexts (Paulston et al. 1975; Kettering 1975; Taylor and Wolfson 1978; Brown 1978). To this end Wilkins (1976) has formulated a notional/functional syllabus. This syllabus grew out of the Council of Europe's decision in the early 1970's to develop a teaching system feasible for teaching all the languages of the Council's member nations. Wilkins (1976) developed the functions and notions for this system as follows: the notional part of the syllabus (Wilkins 1976) refers to "semantico-grammatical categories" or those categories which are grammatically formalized such as time, quantity, and frequency. The functional component are those semantic categories which are not evidenced by 
definite grammatical forms such as modality, suasion, argument, interpersonal relations, and others (Ross 1981, p. 227). Munby (1981) using Wilkins's (1976) functions, has designed a detailed communicative syllabus which can be focused on the individual needs of a learner. This quality is one Briere (1980) mentions as being a goal of research plans to develop a total model of communicative competence (p. 92). Briere conceives the model as a prerequisite to any full-fledged communicative competence testing in ESL. In his view, tests of limited aspects of communicative competence are possible however. Some studies addressing this issue of limited tests are discussed later on in this section.

There has not, in fact, been very much empirical testing labelled with communicative competence. Savignon's (1972) experiment was one that was so designated. Her research dealt with the relationship between grammatical competence and communicative competence. Her subjects were three groups of American students studying first year French in an American university. All three groups received like number of grammatical instructional hours each week. One group had an extra hour per week of communicative activities where "getting the meaning across" was stressed. The second group spent an additional hour in a "culture lab" where, for example, French movies and art slides were shown. The third group spent the additional 
hour in the language Jab. Savignon discovered through standardized reading and listening comprehension testing that there were no significant differences between the three groups in grammatical competence. The "communicative competence" group (the first group), though, scored significantly higher than the other two groups on four communcative tests she developed. These tests were a discussion task, an information getting interview, a reporting task, and a description of actions task. For evaluating these communicative tests, Savignon used the criteria of effort to communicate and amount of communication--discussion; comprehensibility and suitability of introduction and conclusion, poise, and naturalness of interview conduct, and how much the rater understood--interview; fluency and comprehensibility--reporting and description. A six-point scale labelled from "none" to "great" was used for scoring. While Savignon suggests from her research that "there is indeed a difference between linguistic competence (grammar) on the one hand and communicative competence on the other" (1972, p. 52), she offers no description of the grammatical skills required in the description task, for example, nor is there empirical backing for the evaluation criteria.

Canale and Swain (1979) mention other research conducted by Tucker which demonstrates that grammatical competence is not necessarily a good indicator of communicative skills. Two groups of ESI students are contrasted. One 
group scored very high on the Michigan Test of English Language Performance (95\%) and the TOEFI test which primarily test grammar skills while the other group was in a lower (60\%) percentile. The subjects were given four communicative tasks to perform orally, as in a describing task. Tucker found that those scoring low on the proficiency tests "were able to communicate as effectively and rapidly in English as were the individuals of high measured proficiency in English" (Canale and Swain 1979, p. 30). It should be remarked that Tucker is comparing scores from written exams with those from oral production tasks.

In light of Briere's view that various aspects of communicative competence can be tested, it is pertinent to acknowledge Cohen and Olshtain's (1981) research of one example of sociocultural competence. Sociocultural competence is defined here as the ability to use target language knowledge in communicative situations. In attempting to devise a scale to measure control of cultural appropriateness and style, the authors focused on "apology." Employing eight role-play situations, native Hebrew and English speakers were asked to apologize in Hebrew, as nonnative English speakers and in English. A crosscultural evaluation was then carried out on the nonnative English responses analyzed in terms of the native Hebrew and English responses. From this, while both culturally and stylistically inappropriate responses were discovered, 
Cohen and Olshtain (1981) felt that the study suggests that the nonnative English speakers "utilized, for the most part, the same semantic formulas as native English speakers, when their proficiency permitted it" (p. 130). The authors noted that paralinguistic data was not analyzed but were significant especially in the case of apology (p. 129).

Another specific communicative competence component research project was carried out by Carrell and Konneker (1981). The authors investigated native American English and nonnative ESL learners' judgments of politeness. They discovered that intermediate and advanced ESI students do judge statements of politeness on request strategies similarly to native speakers. One major difference noted was that second language learners "tend to perceive more politeness distinctions than do native English speakers" (p. 27). Carrell and Konneker suggest that this may be due to an "over-sensitivity" that expects differences in form to be consistent with differences in communicative intent (p. 27). The importance of this study, and that of Cohen and Olshtain (1981), lies in the inclusion of first language baseline data as well as second language data. There is empirical research relevant to a test of oral communicative competence that comes under the heading of oral proficiency. It is generally conceded that the oral interview is the best way to determine a student's "ability to communicate orally in face-to-face language 
situations (Clark 1978, p. 24). The best known language test of this so-called "direct" test type is the Foreign Service Institute Oral Interview. It has proved highly face-valid in assessing a speaker's ability to perform in a target language (Wilds 1975, p. 35). But because it needs constant maintenance of testing and scoring standards, "it is therefore not ideal for the normal academic situation where all testing comes at once. . and where using two teachers to test each student would be prohibitively expensive" (Wilds 1975, p. 35). The FSI Oral Interview has five proficiency levels for speaking and reading: elementary, limited working, minimum professional, full professional, and native or bilingual. At the time of the test, the examinee is rated by the following factors and weights: accent, o; grammar, 3; vocabulary, 2; fluency, 2; and comprehension, 2 (Wilds 1975, pp. 36-38). These factors seem generally accepted for oral testing (Folland 1976; Bacon and Ojanen 1976; Binham 1976).

Very recently, however, there has been some evidence (Mullen 1980; Scholz et al. 1980; Oller 1980; Yorozuya and Oller 1980) that these FSI proficiency factors may actually be a unitary factor and that "dividing oral performance into components is superfluous at best, and artificial at worst. According to the best available empirical evidence, a listener apparently does not and perhaps cannot componentialize the characteristics of speech. Rather it 
would appear that overall comprehensibility is what motivates the evaluation" (Callaway 1980, p. 111). Yorozuya and Oller (1980) suggest that it is possible that for oral testing, a careful evaluation of "overall communicative effectiveness" could be as effective as the separate scale ratings of the FSI oral interview type (p. 152).

Nicholson (1981) describes preliminary research undertaken to improve an existing interview testing procedure. In the original test, students were given overall subjective ratings for listening and speaking.' For the new test the student is asked to paraphrase the content and describe the context of five different prerecorded conversations. It is assumed that for integrative testing "normal speaking and listening require a full complement of integrated language skills. Understanding the context of a communication event should be as central to overall competence as understanding the . . content" (p. 25). Nicholson reported that the new test's combined scores correlated highly with scores to a cloze test, another integrated test.

Turning from the "direct" oral test, or interview, there are what are termed the "indirect" and "semi-direct" oral tests. Indirect tests do not require active speaking by the examinee. Semi-direct tests elicit active speech by the examinee using "non-human" (tape recordings, printed matter) devices. One often mentioned indirect method of 
determining speaking ability is the cloze test. This involves deleting every nth word of a passage, normally around 50-100 deletions, which the examinee must fill in with a suitable word. High statistical correlations have been discovered between cloze tests and more face-valid tests of active speaking ability (Hinofotis 1979) but as Clark (1979) states, this relationship is "generally not a convincing demonstration of the examinee's actual competence in active speech production" (p. 36).

Semi-direct tests, which Clark (1979) sees optimally used for measuring achievement ( $\mathrm{p}$. 38), have reliability fluctuations depending on the specific kind of test items and scoring procedures (p. 42). When the test type tends to be more objective (structural drills, vocabulary items) the reliability would probably be sufficiently high. If the test rating procedures are too general or call for discriminations raters are unable to make easily, the scoring reliability may not be any higher, or even lower than an interview type direct test of oral proficiency (p. 43)

Recently Educational Testing Service has developed a semi-direct TOEFL speaking test. The research undertaken for this endeavor uncovered important results. In order to establish validity for the test, an oral interview of both 20 and $5-6$ minutes were administered to the same group of subjects. According to a Progress Report (1978?), 
inter and intra-rater reliability was acceptably high for both interviews and the shorter interview was found to correlate quite highly with the longer interview.

The speaking test itself included item types compatible with tape/booklet administration in an operational setting. The item types ranged from very highly specific language tasks such as noun and verb vocabulary, to more general tasks approximating real-life speaking activities such as simulated phone conversation and persuasive speech (Clark 1979, pp. 46-47).

Several significant considerations were dealt with during the development of the TOEFI Speaking Test as reported in the Progress Report (1978?). First, there is the natural and inextricable relationship between listening comprehension and speaking. It is considered "difficult, quite artificial, and indeed counter-productive to attempt to develop a speaking test that would not draw at least to some extent on listening comprehension" (p. 2). Second, the situations used in the test should be restricted to those a nonnative student would have a reasonable probability of meeting during his stay in the U.S. Third, as stated previously, both more and less highly structured item types would be necessary to accomodate speed and objectivity in scoring, yet adaressing the problem of face validity. Fourth, the technical problems and costs of administration were outlined. Testing of this kind 
would require the use of two tapes (one for spoken stimuli, another for examinee response) which may inhibit the test's use in some locations. While the aurally presented material is kept simple and straightforward, there will be a test booklet coordinated with the test tape available. Finally, the test at this point is norm-referenced as it gives a relative ranking on a (test defined) general index of "Ianguage proficiency" but does not detail specific real-life tasks that the examinee would be considered able to carry out in an appropriate manner (Progress Report 1978?, p. 2).

Another oral testing research project which merits discussion here is that conducted by Levenston (1975). His overall goal was to help alleviate cross-cultural misunderstandings that arise from inappropriate verbal behavior in social situations (p. 67). The preliminary study presented here reports that about fifty immigrants of various linguistic backgrounds and proficiency levels and a comparable number of native speakers were orally asked how they would respond to approximately sixty daily life situations. The kind of verbal (oral) behavior required included request, complaints, apologies, excuses, invitations, congratulations, praise, blame, criticism, and reactions to all the above ( .68$)$. The native replies would then provide a basis on which to evaluate the nonnative responses. As noted above, Cohen and Olshtain (1981), and Carrell and Konneker (1981) also followed this procedure. 
In terms of scoring, Levenston (1975) feels that accuracy (grammatical, lexical, and phonological) and situational appropriateness should be scored. He then describes three degrees of appropriateness "quite independent of accuracy: (a) fully appropriate in form and content, (b) appropriate in content but not in form (even though grammatically well formed), and (c) inappropriate in content" (p. 71$)$

Since this was just a preliminary study, there were no empirical conclusions to present. However, the concept of situational testing which is evaluated on the basis of native speaker responses for both accuracy and appropriateness was an important step in the process of speaking test development.

Spolsky et al. (1975) described an experimental pragmatic test which attempts to measure communicative competence. It is called the Oral Placement Test for Adults and is used to place nonliterate adults in suitable levels of an ESL program. The proficiency scale used for the test was developed out of one made available through the National Association of Foreign Student Advisors (NAFSA). It gives general rating descriptions for aural comprehension and speaking skills on four levels (p. 90). The test itself consists of four blocks: seven straightforward questions on personal details; fourteen simple sentences to be repeated in order to check pronunciation; 
a short conversation generated from more complex questions, followed by items requiring grammatical structural changes; and ten sentences to be transformed either into past or future tense. These are rated "acceptable" or "not acceptable." The test thus combines both a "real sociolinguistic situation with certain discrete point items" (Spolsky et al. 1975, p. 85). The entire test takes from 2-7 minutes to administer and score and has shown a satisfactory level of inter-scorer reliability (p. 86), though the training required to become an administrator is not extensive.

Projecting what a "discrete-point" test of communicative competence might look like, Morrow (1979) has proposed the following aspects of a communication interaction for assessment by a learner: (a) the settings to which it might be appropriate; (b) the topic which is being presented; (c) the function of the utterance; (d) the modality/ attitude adopted by the speaker/writer; (e) the presuppositions behind the utterance; ( $f$ ) the role the speaker/ writer is adopting; (g) the status implicit in the utterance; (h) the level of formality on which the speaker/ writer is conducting the interaction; and (i) the mood of the speaker/writer (p. 54). This itemized proposal seems to be reminiscent of Hymes's SPEAKING acronym mentioned in the previous section (see p. 14).

Morrow (1979) also gives general suggestions concerning the characteristics of a performance-based, 
integrative test of communicative competence. First, it will be criterion-referenced against the operational performance of a set of authentic language tasks. In other words, it will set out to show whether or not (or how well) the examinee can perform a set of specified activities. Second, it will be crucially concerned to establish its own validity as a measure of those operations it claims to measure. Thus, content, construct, and predictive validity will not necessarily be significant. Third, it will rely on modes of assessment which are not directly quantitative but which are instead qualitative. It may be possible or necessary to convert these into numerical scores, but the process is an indirect one and recognized as such. Fourth, reliability, while clearly important, will be subordinate to face validity. Spurious objectivity will no longer be a prime consideration, although it is recognized that in certain situations test formats which can be assessed mechanically will be advantageous (Morrow 1979, p. 150). These suggestions, which Morrow acknowledges need further exploration, provide an interesting contrast to the considerations discussed by the TOEFE Speaking Test Progress Report.

One final representative empirical example, this from the communication field's research on communicative competence, should be described. Wiemann (1977), as reported above, proposed a five-part model of communicative 
competence. To test this model, Wiemann used interaction management as the independent variable to partially test the model. The other components--behavioral flexibility, empathy, affiliativeness/supportiveness, and social relaxation--were proposed to have a positive linear relationship between them and perceptions of interaction management. This hypothesis was supported (p. 205). However, a hypothesized parabolic relationship between the level of interaction management and observers' perceptions of communicative competence was not supported (p. 203). Wiemann reached these results by directing subjects to watch a 4-minute tape of an interaction between an oncamera communicator and off-camera confederate. The interactions incorporated one of four possible interaction management treatments on the part of the on-camera communicator varying from rude to high management. The two behaviors manipulated in this study were conversational turntaking synchronization and topic control. The errors in interaction management were primarily nonverbal. The subjects then rated the on-camera communicator on items describing the communicative competence variables using a Likert-type scale. Two examples of variables are: subject finds it easy to get along with others (competence); subject can adapt to changing situations (behavioral flexibility) (p. 205). 
SUVIMARY

As this review of the literature shows, communicative competence is a concept that does not yet have a concise, standard meaning. Iinguists, sociolinguists, discourse analysts, and communication scholars using this term seem to have slightly different perceptions of the idea. However, all of the authors agree that communicative competence is tied in some way to appropriate behavior-socially, linguistically, strategically, and/or culturally. This apparently involves the human capacity to learn how to, and be able to, communicate with other human beings by the rules which govern our verbal and nonverbal behavior. Language testers, following in the steps of the theorists, are presently experimenting with what constitutes a test of communicative competence. Even the understanding of oral proficiency is under scrutiny. Going beyond the considerations of grammatical, or linguistic, competence, some researchers are now investigating functional language use and contextual appropriateness. The purpose of the test, whether to place language students, to check their proficiency, or measure their achievement, will affect the kind of test administered. Oral proficiency or communicative competence tests have tended to be direct interviews, but semi-direct tests have also been formulated, though the challenges of validity, reliability, and 
practicality remain. It was from this background that the following research on semi-direct testing of communicative competence for college level ESI students evolved. 


\section{INTRODUCTION}

In an ESL program with already existing testing procedures for reading, writing, and listening comprehension skills, a speaking test of communicative competence would be an important addition, but would need to consider practical implementation concerns to be usable. As discussed previously, the most obvious oral test, the oral interview test, is an important tool in its way, but the time commitment on the part of both examiners and examinees make it unrealistic for a program of 130 to 170 students.

The Center for English as a Second Language (CESL) at Portland State University began preliminary work on an oral test in 1975 when the interest in evaluating students' speaking skills became recognized. It was felt that this additional tool could help provide a more complete and accurate assessment of a student's language ability. Information on a student's reading, writing, listening, and speaking skill level is useful for placing the student in the proper level of an ESL program. Revised and improved versions of the test were formulated between 1975 and 1979 . The motivation for developing a short, taped, semi-direct test lay in the realization that if it were valid and reliable, it would lessen the need for time-consuming 
individualized interview testing and allow for rating on the basis of personnel availability. It would, of course, also be technically possible for a large number of students to be examined at one time.

\section{OVERVIEW OF THE RESEARCH}

Below is a brief description of the research. A more detailed discussion of each procedure follows this overview.

To carry out the task of developing a test of oral communicative competence for college level ESL students, the criteria that apply to oral communicative competence were selected first. Next, two sets (trial and final) of interview tests and taped tests were developed, administered and rated. Five ESI students, who later took the trial taped test, underwent a trial interview test with the researcher and co-investigator. The students were then rated by the two interviewers for accent, grammar, vocabulary, fluency, comprehension, pronunciation, appropriateness, and intelligibility. After the trial interviews, a 7-minute oral semi-direct test was constructed and recorded by the researcher. The trial taped test consisted of short questions and social situations recorded with time allowances for response. The trial taped test was administered to the five trial test students. The trial 
taped test responses were then rated for three criteria: intelligibility, gramatical correctness, and appropriateness by individual raters. One rater rated for all three criteria. Both of the trial tests' procedures were evaluated for their practicality. The final interview tests then took place. Another 25 ESI students were interviewed and rated by the researcher and coinvestigator. The students were rated for vocabulary, comprehension, grammar, intelligibility, and appropriateness. Following the final interview test, the final taped test was administered to the 25 ESL students. The final taped test was constructed almost identically to the trial taped test. The taped test responses were rated twice for the same criteria as the trial taped test by individual raters with a time lapse between ratings. Once the ratings were completed, a reliability study was conducted on the raters and interviewers. The validity of the taped tests was assessed by determining the degree of association between the taped test results and the interview test results, both for individual criterion and overall ratings. Finally, the degree of association between the students' taped test scores and their scores from the Comprehensive English Language Test of Listening Comprehension (CELT), which the students had taken before entering the ESL program, was determined. 
COIMUNICATIVE COMPELENCE CRITERIA

\section{Intelligibility}

The first task of this research was to select the criteria of oral communicative competence. Past research offers guidelines on what criteria may apply to a speaking test. For this experimental test, three criteria were selected. First, intelligibility was considered important since oral production quality is a factor in communicative effectiveness. Obviously, without accurate comprehension, miscommunication may result. The ESI curriculum at PSU, as well as other like programs, reflects this concern in the teaching of pronunciation or speech for at least three out of four levels of instruction. While research (Smith and Rafiqzad 1979) has pointed out that intelligible speakers of English can be nonnative as well as native, oral tests and research continue to examine the various components affecting oral production. For this particular research the factors that were determined to affect intelligibility were: voice quality; loudness; rate; pronunciation; stress--divided into syllable stress, phrasing, and rhythm; and intonation (see Appendix A). The basic criterion was the ease of understanding the student's oral production. The FSI Oral Interview, as mentioned earlier, rates for both pronunciation and fluency. Mullen (1980) used pronunciation and fluency, among others, as factors in 
her study on raters. Callaway (1980) divided accent into intelligibility, pleasantness, acceptability, and nativeness, but concluded that the scales were probably unitary (p. 109).

From a review of pertinent literature on pronunciation, accent, and speech pathology, a 5-point intelligibility scale evolved. The final scale resembles the National Technical Institute for the Deaf's Speech Intelligibility Rating Scale (1978). Additionally, the voice production components that may affect intelligibility of the subject were listed on the rating sheet for the rater to mark if they were perceived to inhibit the intelligibility. It should be noted that for this research intelligibility is viewed as an oral phenomenon.

\section{Grammatical Correctness}

The second criterion used to assess the student's speaking ability is grammatical correctness (see Appendix $B$ and $C)$. Traditionally, this has been an important component in oral tests. The FSI Oral Interview places the greatest "weight" on gramnar in its ratings. Other interview tests investigating FSI format also necessarily include this factor (Mullen 1980; Yorozuya and Oller 1980). It may be especially important that in college level ESL programs, grammatical correctness in speech as well as writing is one of the primary goals of instruction. 
Levenston (1975) considered accuracy, by which he meant grammatical, lexical, and phonological exactness, as one aspect of his scoring process. The second aspect was situational appropriateness.

\section{Appropriateness}

Appropriateness serves as the third criterion in this testing experiment. For this research appropriateness was assessed in terms of the acceptability of the response in relation to a given social situation (see Appendix $D$ and $E$ ). This includes consideration of wording, formality level, and vocal tone. Wiemann and Backlund (1980) present "appropriateness of behavior" as the criterion of communicative competence. This appropriateness is "determined by explicit and implicit cultural and group norms, efficacy for attaining a goal, and/or common sense" (p. 191). The authors continue, defining appropriateness as the ability of an interactant to "meet the basic contextual requirements of the situation" ( .191$)$. Three contextual requirements are then given. The first is the verbal context which means to make sense in wording, statements, and topic. Second, the relationship context refers to the organization, style, and kind of messages which are complementary to the situational relationship. Third, the environmental context involves the symbolic and physical constraints imposed on the message formulation. The specific behavioral dimensions of appropriateness have been discussed in the previous chapter. 
As an example of inappropriate wording, taken from the taped test situations (see Appendix $F$ ), to reply to the apartment manager that "I really hate this apartment" when you do not like it may be unsuitable in this situation (No. 6, Part 1). Sarcasm used in apologizing to a professor for being late would involve inappropriate vocal tones (No. 2). Saying "Excuse me, please, I am very late to my class and I must go. I hope very much to see you at another time," is an example of both incorrect wording and too formal a speaking level when leaving a friend (No. 3 ).

For this type of research, where the intent is to be able to assess an ESL student's oral competency, it is assumed that the communication situations given in the test will provide a context in which the student can respond appropriately on the verbal and relationship context levels (Wiemann and Backlund 1980).

\section{TRIAL INTERVIEW TEST AND RATING}

Four student volunteers from the ESI program who were later given the trial taped test were interviewed during the week of July 21-25, 1980. The fifth trial test student was interviewed the first week of August (see Table I). The two interviewers were the researcher, who was a graduate. student in Speech Communication and an ESI teacher for five years, and a teaching ESI student co-investigator who had lived abroad as a nurse and teacher for two years. 
TABLE I

TRIAL TEST SUBJECTS

\begin{tabular}{l|lcc}
\hline \hline \multicolumn{1}{c}{$\begin{array}{c}\text { Instruction } \\
\text { Level }\end{array}$} & Language & Sex & $\begin{array}{c}\text { Graduate (G) } \\
\text { Undergrad. (UG) }\end{array}$ \\
\hline $\begin{array}{l}\text { Level 1 } \\
\text { Beginning }\end{array}$ & Arabic & M & UG \\
& Portuguese & M & UG \\
$\begin{array}{l}\text { Level 2 } \\
\text { Lower Inter- } \\
\text { mediate }\end{array}$ & Arabic & M & UG \\
$\begin{array}{l}\text { Level 4 } \\
\text { Advanced }\end{array}$ & Korean & M & G \\
\hline
\end{tabular}

The interviews took place in a classroom nomally used for ESL tutoring and classes. The specific area where the interviews were carried out was partitioned from the rest of the room and afforded privacy and unimpaired listening. The subjects and two interviewers were seated at lecture desks. This room was chosen for its availability and primarily for its familiarity to the students.

Beginning with introductions of the interviewers if not already known to the subject, the interview proceeded to general information questions about the student. For example, the student's major, length of time in the United States, plans for vacation, and reasons for studying English were asked about. These were used to check the student's choice and use of vocabulary and comprehension level. If the student seemed able to answer these questions with little difficulty, they were then asked more 
analytical questions such as differences between American culture and their own, problems in learning a language, or opinion questions on recent newsworthy events. The student was encouraged to discuss a topic of interest to him or her in as much detail and complexity as their language ability would permit. At the end of the time the student was thanked for coming and for helping with the research project. The interviews lasted from 10 to 30 minutes. Generally, one interviewer tended to ask the questions while the other attended to the rating features.

After the student left, she or he was rated independently by the two interviewers on a 5-point scale for the following criteria: accent, grammar, vocabulary, fluency, comprehension, pronunciation, appropriateness, and inteligibility. The 5-point rating scale was taken from the FSI Oral Interview proficiency ratings. The first 5 performance factors were also taken from the FSI interview (see Appendix $C$ ). The pronunciation rating was based on vowel/ consonant error percentages. The intelligibility rating was based on that from the Technical Institute for the Deaf (1978) and was the one used in the final rating (see Appendix A). The appropriateness rating was based on the congruency of displayed language, verbal and nonverbal, and behavior with the expected norms of behavior within the context of the interview. Considered in the context was role relationship, student to interviewers; time, during 
the school day; place, classroom; interaction type, consultative; and the verbal and total nonverbal channels. Specific behaviors attended included greetings, introductions, leave takings, body posture and haptics, formality level, and eye contact (see Appendix E for complete description of the 5-point scale). The total possible points ranged from 3-40. The trial interview ratings were used only to collect feasibility data, not final analysis data.

\section{TRIAL TAPED TEST AND RATING}

\section{Content of the Test}

After the trial interviews, the taped test was constructed. The taped test consists of three parts. The first part is the general introduction to the test (see Appendix F for the final version of the taped test script). The second part is the short questions and answers section. These questions are those frequently asked of foreign students and are thus meant to acquaint the test subjects with the test format under somewhat familiar conditions. They were also meant to familiarize the rater with the speaking and listening abilities of the subjects before commencing the ratings. The third part are the communication situations. The subjects were instructed to respond to them in an appropriate manner. The responses to these situations comprised the data which was rated. The communication situations were selected to provide context for the student 
to respond to, and were chosen, as in TOEFL (1980), for their likelihood of a foreign student encountering them. It would have been unrealistic to include every communicative "function" (see Wilkins 1976). Situations were selected to furnish contexts incorporating some of those verbal vehaviors considered valuable for an ESL student to master. These were: apologizing, leave taking, asking directions, complaining, describing, refusing, complimenting, and introducing. The situations further designated a role relationship and formality level.

\section{Practicality of the Taped Test}

The present test was designed to be practical to administer in terms of length. The tape required a total of approximately 7 minutes of student listening and oral response time. The instructions explaining the purpose of the test, five short information questions to be responded to, and ten situations to be responded to were recorded on a tape. Thus the test is usable by anyone familiar with tape recording equipment. Further, for rating purposes, the instructions at the beginning were normally omitted during the tape duplicator transposition process. This resulted in a tape only 5 minutes in length, which could be rated at the rater's convenience.

In a departure from other tests, this one was exclusively oral. There were no written instructions, pictorial 
devices, or test items for the subjects to follow as the tape progressed. This freedom from passing out and collecting testing paraphernalia facilitates the speed of test administration. Every effort was made to insure the simplicity and clarity of both the taped instructions and the two sections requiring a subject to respond, since they were delivered only once. This procedure appeared justified in that, as the TOEFL Progress Report (1978?) notes, an oral test is linked to the ability to comprehend aural cues.

\section{Trial Taped Test and}

Rating Procedures

In order to determine the feasibility of an oral taped test, the same five subjects who participated in the trial interview test were also given a preliminary version of the oral taped test. The researcher taped all parts of the test: instructions, short questions, and communication situations. At a later time the subjects individually listened and responded to the tape during the week of July 27-31, 1980. The total test time per subject was approximately 7 minutes. The testing took place in the Leaming Laboratory at PSU at a time convenient for the subjects. The responses were then rated on the three criteria scales of intelligibility, grammatical correctness, and appropriateness (see Appendix A, B, and D). The raters indicated no significant problems in implementing the 
rating scales which were constructed for accuracy and ease of rating with little or no training required. The results of the ratings showed a high degree of consistency for each scale. Two raters rated only for one scale each. One rater rated for all three scales. A total of 7 raters were used.

\section{Raters}

A profile of the raters, who participated in both the trial and final taped test ratings, reveals that they are all ESL teachers or have been in the recent past except one, who has had substantial contact with ESL students and traveled abroad. Three reasons justify this. First, the literature shows that the difference in ratings between teachers and naive judges on oral proficiency scales is slight (Mullen 1980). Second, ESL instructors are the persons most likely to be used as raters in the event that a test such as this be administered in the English program. Third, feedback from ESI teachers about the rating process was helpful in assessing this study.

\section{FINAL INTERVIEWS AND RATINGS}

Following the trial interview tests (and trial taped test), some changes were made in the interview procedure. First, the seating arrangement was altered so that the interviewers and interview subject were all easily visible to one another. Second, the rating features were 
consolidated from eight to five. The components rated for the final interviews would be comprehension, grammar, and vocabulary from the FSI definitions, intelligibility based on the rating scale from the speaking test, including a noting of the oral production components inhibiting the interviewers' comprehension, and, lastly, appropriateness. It was realized that the fluency, accent, and pronunciation ratings were redundant in light of the intelligibility rating capabilities.

The 25 students from the ESI program, almost all of whom volunteered on were asked by their teachers to participate in the final testing project, were interviewed individually by the researcher and co-investigator (see Table II). These two native American English speakers were the same interviewers who conducted the pretest interviews. The interviewers strived to maintain a consultative style of speaking. They also strived to enunciate clearly without affectation. The interviews were held in the same location as the pretest interviews. Scheduled 15 minutes apart during the first week of August, 1980, the interviews were held either at the noon hour or after the ESI classes were completed for the day. Due to early or late arrivals and no-shows, most students were interviewed for more than 15 minutes and every student was interviewed for at least 10 to 15 minutes. 
TABLE II

FINAL TEST SUBJECTS

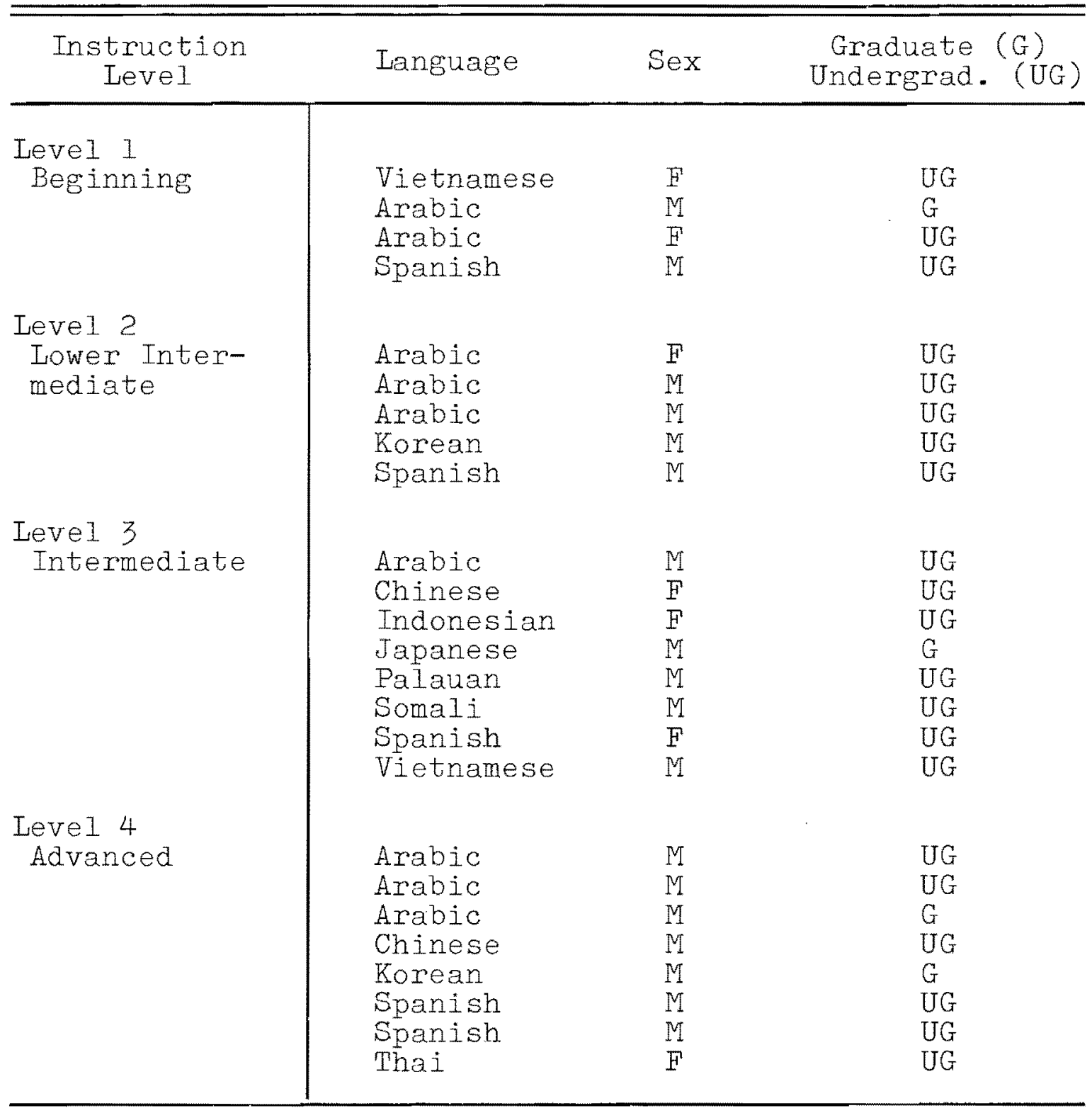

Greetings and introductions, if necessary, began the interview. As in the pretest interviews, the student was then asked general information questions. Usually these questions elicited enough language to enable the interviewers to determine the general level of the student based 
on the complexity and correctness of grammar, vocabulary choice, whether limited or extensive, comprehension ability (if questions needed to be repeated or simplified or uttered more slowly), and intelligibility.

From this point, if time permitted and the student was interested, further discussion followed. The students generally seemed to welcome the opportunity to practice conversing in English with Americans who wanted to talk to them. At this point, more probing questions were asked in order to check the student's skill at describing an object or process, expressing an opinion, analyzing a problem, or giving directions on a topic in which she or he seemed knowledgeable and interested. This gave the interviewers more opportunity to observe vocabulary and grammar strengths and weaknesses. Also comprehension, intelligibility components, and appropriateness of behavior and language could be further evaluated. At the end of the time the student was thanked for coming to the interview and for helping with the research. The interviewers could observe whether the student could recognize the verbal and nonverbal cues for leave taking at this juncture.

Before the actual interview began, or after the student had been thanked for his participation in the interview, she or he was requested to fill out the Interaction Questionnaire and sign up to record the Speaking Test. The Interaction Questionnaire was constructed to obtain 
data on a student's experience with studying and interacting in English (see Appendix G). The information acquired in this manner was not used in the final analysis of this experiment, but was collected to provide input for further research.

After the student had departed from the interview location, he or she was rated independently by the two interviewers on a 5-point scale for the following criteria: grammar, vocabulary, comprehension, appropriateness, and intelligibility, with the comprehension inhibitors noted (see Appendix A, C, and E). The possible total points ranged from 5 to 25.

\section{FINAL TAPED TEST AND RATING}

After the trial taped test, two changes were made on the taped test to address the issue of validity. First, the taped voices eliciting responses were changed to alternate between male and female rather than being exclusively female. Every effort was made to insure a clear, standard style of speaking. Second, the order of the communication situations was rearranged to preclude the possibility of pretesters preparing any of the final subjects.

The final test tape was initially recorded on the 3-3/4 ips speed of a Sony 777-2 half-track, two-speed (3-3/4 ips/7-1/2 ips) recorder. The response time spaces were monitored at 6 seconds for the short questions section 
and 14 to 15 seconds for the communication situations section. Three copies were then duplicated on a Viking 235 duplicator. This permitted up to three subjects to take the test simultaneously. The subjects heard the tape in the Learning Laboratory from a Viking 75 playback machine and recorded their responses on either an Instructo-matic CRI Booth Recorder or a Telex Lab Series 452 Recorder. The subjects' recordings were completed over a week's time at the end of the Summer Term, 1980, at the convenience of the subjects.

After all of the recordings were finished, the tapes were transposed on the duplicator into standard cassette format. In the process the initial instructions were normally omitted, reducing the length of each subject sequence to approximately 5 minutes. It was now possible to rate the tapes. The raters rated the tapes at their convenience for a total of two times, with a time interval varying from 2 weeks to 3 months.

Written instructions were given to the raters, explaining the focus of the particular rating scale--appropriateness, grammatical correctness, or intelligibility (see Appendix A, B, and D for sample rating scales and notes to raters). The ratings were made only on the communication situations, not the short answers. The intelligibility scale was designed as a 5-point tikert-type scale with descriptors from completely unintelligible to completely intelligible, resembling the Technical Institute 
for the Deaf's Intelligibility Rating Scale (1978). As part of intelligibility, oral production components were also listed for post-rating evaluation of specific production problem areas. The grammatical correctness took a yes/no/no response format from which a percentage of correctness can be calculated. The appropriateness scale was likewise in a yes/no/no response fomat. The total points possible for all three criteria ranged from 10 to 70 . Seven raters were used to undertake the ratings. Two raters rated for each scale separately. One rater rated for all three scales. The ratings were performed twice with a time lapse from 2 weeks to 3 months apart.

\section{RELIABILITY STUDY}

At the conclusion of the taped test ratings a testretest reliability study was performed on the experimental (final) taped test. A correlation coefficient was computed to measure the degree of association between the ratings of the taped test for the first and second rating sessions.

Intra-rater and inter-rater scores for each test criterion must correlate significantly in order to establish the reliability of this testing procedure. To determine the reliability of the taped test, the following hypotheses were formulated:

Hypothesis I: The ratings assigned by an individual rater will not vary significantly from one rating of the test to the other. 
Hypothesis II: The ratings assigned by all three raters for one test criterion will not vary significanty between the raters.

To avoid the "halo" effect (Oller 1980), two different raters were used to rate each criterion and two ratings were performed, from 2 weeks to 3 months apart. A third rater was used to score all of the criteria. Again, two ratings were performed with a 2 month's time lapse between them. For each criterion, then, there was a total of three raters.

In addition, the degree of association between the two interviewers' ratings was computed to establish interrater reliability for the final interview test. The results of the reliability study are set forth in the next chapter.

\section{CONCURRENT VAIIDITY}

In addition to the issues of reliability and practicality, there is also the consideration of validity that is important in the development of a testing instrument. To establish concurrent validity, three hypotheses were formulated. They are:

Hypothesis I: An overall rating assigned to a subject on a test criterion from the taped test will not vary significantly from the rating on the same criterion taken from the interview. 
Hypothesis II: An overall rating assigned to a subject from the taped test will not vary sig-. nificantly from the overall rating on the interview test.

Hypothesis III: An overall rating assigned to a subject from the taped test will not vary significantly from the score assigned to the subject on the CEIT, a standardized listening comprehension test.

Thus, to determine validity, every subject not only took the experimental taped test in the language lab, but also underwent a face-to-face interview by the researcher and a confederate beforehand. The interview, which is considered to be a face-valid measure of proficiency, has been suggested as a suitable method of establishing the validity of a semi-direct test (Clark 1979, p. 40). A high correlation between the scores from a face-valid interview and the taped test, both rated for the same criteria, should produce sone measure of validity for the semi-direct test. In addition, scores on the CEIT were obtained from 20 of the same subjects before they entered the ESL program. Four subjects did not take this test for placement in the ESI program. One subject's score was 2 years old and was therefore considered invalid for this research. 
Briefly, the Comprehensive English Language Test (CEIT) of listening comprehension is a multiple choice, 50-item (100 point) test that was developed and validated with reference to nonnative speakers of English. It is designed to assess nonnative speakers' ability to comprehend spoken English. The test has three parts: part one is questions and answers, part two is understanding statements, and part three is comprehending dialogues. The test items are given orally on a tape and the examinee has a test booklet with the multiple choice answers written out from which to select one. The results of the testing of these three hypotheses concerned with the validity of the taped test as well as the reliability study are reported in the next chapter. 
CHAPTER IV

\section{ANALYSIS AND DISCUSSION OF RESULTS}

\section{INTRODUCTION}

This chapter will analyze the results of the experimental test. Specifically, it will present a profile of the scores obtained from the final taped test and the interview test. The results of the reliability study performed will be given next. Finally, the hypotheses constructed to establish the validity of the taped test will be discussed.

\section{PROFILE OF THE TAPED TEST} AND INTERVIEW SCORES

Recalling the scoring system used for the taped test, a total of 70 points is possible. These are divided into three individual scorings or ratings for the three criteria. Intelligibility has a range of 10 to 50 points; Grammatical Correctness has a range of 0 to 10 points; and Appropriateness has a range of 0 to 10 points. Thus, a total score that a subject could achieve would range from 10 to 70 points. After computation, the mean score for all of the subjects was 52.09 (see Table III for a profile of scores). 
TABIE III

PROFILE OF SCORES

\begin{tabular}{|c|c|c|}
\hline \multicolumn{3}{|c|}{ Individual Scores by Instruction Level } \\
\hline Level 1 & Level 3 & Level 4 \\
\hline $\begin{array}{l}28.16 / 5 / 24^{2} \\
47.34 / 5 / 34 \\
51.50 / 6 \\
52.17 / 10.5 / 24\end{array}$ & $\begin{array}{l}43.83 / 9 / 62 \\
48.49 / 8.5 / 66 \\
49.84 / 6 / 38 \\
51.67 / 10 \\
53.00 / 8 \\
53.35 / 9 / 70 \\
55.00 / 9 / 46 \\
62.83 / 10 / 56\end{array}$ & $\begin{array}{l}45.67 / 9.5 / 52 \\
52.67 / 11.5 / 92 \\
55.00 / 7.5 / 54 \\
56.67 / 10 / 62 \\
56.84 / 10 / 46 \\
59.01 / 10 \\
59.33 / 9.5 / 78 \\
59.50 / 10 / 68\end{array}$ \\
\hline \multicolumn{3}{|c|}{ Group Mean Scores by Instruction Level } \\
\hline $44.79 / 6.63 / 27.33$ & $52.25 / 8.69 / 56.33$ & $55.59 / 9.75 / 64.57$ \\
\hline \multicolumn{3}{|c|}{ Range of Scores by Instruction Level } \\
\hline $\begin{array}{l}28.16-52.171 \\
5-10.51 \\
24-34\end{array}$ & $\begin{array}{l}43.83-56.66 \\
4.5-10.51 \\
38-50\end{array}$ & $\begin{array}{l}45.67-59.50 / \\
7-11.51 \\
46-92\end{array}$ \\
\hline \multicolumn{3}{|c|}{ Overall Mean Scores } \\
\hline Taped Test: 52.09 & Interview Test: $\quad 8.60$ & CEIT: $\quad 52.40$ \\
\hline
\end{tabular}

ascoring as follows: Taped Test/Interview Test/CEIT 
By instruction level, the means were: Level 1--28.1652.17; Level 2--43.83-56.66; Level 3--43.83-62.83; and Level 4--45.67-59.50. There is then more difference between Level $I$ and the other levels than between the highest three levels. However, the dispersion around the mean by level is revealing. For Level l, three subjects were below the total mean, one above. For Level 2, two subjects were below the total mean, three above. For Level 3, four subjects were below the total mean, four above. For Level 4, one subject was below the total mean, seven above.

Recalling the scoring system for the interview test where the scores ranged from 1 to 5 for each criteria, there was thus a score range of 3 to 15 for the three criteria applicable to the final rating. These criteria are the same as those used in the taped test rating: Intelligibility, Grammatical Correctness, and Appropriateness. Following computation the total mean score from the interview test was 8.60 . By instructional level, the mean scores were: Level 1--6.63; Level 2--8.20; Level 3--8.69; and Level 4--9.75. The score range within the instructional levels was as follows: Level 1--5-10.5; Level 2--4.510.5; Level 3--6-10; Level 4--7-11.5. In the case of the interview scores, then, the range of scores by instructional level is not particularly revealing, there not being more than a 1.5 difference between the levels at the higher and 
lower ends of the ranges. The mean scores of each instructional level show more separation between the levels, although Levels 2 and 3 are separated by only .49. There generally appears to be three blocks of scores--low, middle, and high for the taped test and interview test. Even for the CELI (see Table III) the total range of scores for Level 1 is somewhat lower than Level 2, which has the same low end range score as Level 3. Level 4 scores are somewhat higher than Levels 2 and 3 .

\section{RELIABILITY STUDY}

A reliability study was performed by computing a correlation coefficient to measure the degree of association between the first and second ratings of the taped test. This procedure was used to establish the intra-rater reliability of the taped test. Guilford's terminology for degree of correlation is used. It is thus: < .20 slight, almost negligible relationship; .20-.40 low correlation, definite but small relationship; $40-.70$ moderate correlation, substantial relationship; $.70-.90$ high correlation, marked relationship; > .90 very high correlation, very dependable relationship.

For each criterion there were three raters who rated the test tapes twice. For Intelligibility, the first rater's ratings established a high correlation of .90 . The second rater established a high correlation of .88 . 
The third rater established a correlation of .95 , a very high correlation. Thus the raters were highly reliable in their ratings on this criterion of the taped test. For Grammatical Correctness, the first rater's rating established a correlation of .81, a high correlation. The second rater achieved a correlation coefficient of . 36 , a low correlation. The third rater established a correlation of .69 , a moderate correlation. For this criteria, then, the correlations ranged from low to high. For Appropriateness, the first rater's ratings established a very high correlation of .97 . The second rater established a very high correlation of .94. The third rater established a moderate correlation of .69 . Two of the raters for this criterion thus established very high correlations in their individual ratings of the taped test while the last rater established a moderate correlation.

These correlations of the individual criteria illustrate the ability of a rater to rate with some degree of similarity over time. From these data, it appears that both intelligibility and appropriateness are criteria that can be rated with a generally high degree of reliability according to the format developed in this research. However, it appears that grammatical correctness is a less reliably rated criterion. While it was assumed that ESI teachers would have a fairly uniform judgment of what is, or is not, gramatically correct, this may not be the case. 
One rater, the second rater of this criterion, and the only non-ESL teacher, was especially unreliable. The rater who rated for all three criteria, rater 3 , the researcher, established a correlation coefficient of .69 for both grammatical correctness and appropriateness. For Intelligibility the rater established a correlation of .95 . Thus a rater who rates for all the criteria at once can apparently rate at a level of moderate to very high significance. Multiple correlations were also computed to establish the inter-rater reliability of the taped test raters. For Intelligibility, Rzxy $=.77$. Thus the raters together established a high correlation between their ratings. For Grammatical Correctness, the multiple correlation was computed to be Rzxy $=.77$. A high correlation thus exists between the raters' ratings for this criterion. For Appropriateness, the multiple correlation was computed to be Rzxy $=.84$, a high correlation. All of the criteria thus established a high degree of inter-rater reliability. The reliability study then shows that the taped test has established a high degree of reliability for both the intra-rater reliability factor and the inter-rater factor. The exception to this is the intra-rater reliability of Grammatical Correctness.

In addition to the reliability study of the taped test raters, a reliability study was performed on the interviewers. Only one set of data was available as the final 
interviews were conducted one time each per subject. The independent ratings made by the interviewers on the three criteria used in the taped tests were summed to provide the data used. The degree of association was computed to establish the correlation coefficient at $r=.74$, a high correlation. The interviewers therefore maintained a high degree of reliability in their ratings.

\section{CONCURRENT VAIIDITY}

To establish the concurrent validity of the taped test, there were three hypotheses proposed. They are: Hypothesis I: An overall rating assigned to a subject on a test criterion from the taped test will not vary significantly from the rating on the same criterion from the interview test.

Hypothesis II: An overall rating assigned to a subject from the taped test will not vary significantly from the overall rating on the interview test.

Hypothesis. III: An overall rating assigned to a subject from the taped test will not vary significantly from the score assigned to the subject on the CEIT, a standardized listening comprehension test.

The testing of the first hypothesis was accomplished by computing the correlation coefficient to measure the 
degree of association between the overall rating given to a subject on the taped test and the rating given to the subject on the interview test for the same criterion. For the Intelligibility criterion, the degree of association computed was $r=.39$. The significance of this computed by the t-test is $2.03, \mathrm{p}<.1$. For the Appropriateness criterion; the degree of association was computed at $r=$ .67. The significance of this computed by the t-test is 4.34, $p<.01$. For the Grammatical Correctness criterion, the degree of association was computed to be $r=.29$. The significance of this was computed by the t-test to be 1.45 , $p<.2$. If an arbitrary significance level is set at $\mathrm{p}<.05$, then the Appropriateness criterion is the only one that has an acceptable degree of validity, and the hypothesis as a whole must be rejected. In testing for the second hypothesis, comparing the overall ratings from the taped test with the overall ratings of the interview test, the degree of association was computed by establishing the correlation coefficient as $r=.57$. The significance of this was computed by the t-test to be $3.33, p<.01$. Thus this hypothesis can be accepted if the significance level of $p<.05$ is applied.

The third hypothesis was tested by establishing the degree of association between the taped test and the standardized listening comprehension test, the CELT. The correlation coefficient was computed at $r=.42$. The 
significance of this was computed by the t-test to be 1.96 , $\mathrm{p}<.1$. If the significance level of $\mathrm{p}<.05$ is applied, then this hypothesis must be rejected.

In summary, the testing of the hypotheses concerning validity shows that the overall rating on the taped test correlates acceptably with the interview test, thus supporting hypothesis II. As noted previously, this degree of association between a face-valid measure of proficiency and a semi-direct test is most important to establish the validity of the semi-direct test (Clark 1979). The results indicate that the taped test could probably be used as a measure of overall oral proficiency, or oral communicative competence for three levels.

The rejection of hypothesis I due to the low degree of association between individual criteria on the taped test and interview test may reflect the conclusion reached by Callaway (1980) that listeners, here the interviewers, perhaps cannot divide up the characteristics of speech, but instead attend to overall comprehensibility. In light of this, it is interesting that the appropriateness criterion, the one most intrinsic to communicative competence, was the criterion for which a significant degree of association was established between the interview test and the taped test.

The rejection of hypothesis III, which assessed the degree of association between an overall rating score on 
the taped test with a score from the CEIT test probably indicates that the tests are examining different aspects of language ability. The listening comprehension test focuses on the receptive skills of oral comprehension and reading, while the interview test and taped test require both receptive and productive skills.

\section{LIMTTATIONS OF THE TEST}

The limitations of an experimental test such as this are considerable. Most of the problematic issues lie in the realms of reliability and validity. First, in an effort to be practical for administration and rating, the test is short in length. It is possiole, however, that the amount of ratable data from the subjects' "free" responses was not sufficient in all cases, or any case, for the raters to rate in a reliable manner. Also, the raters may require more training than originally envisioned, especially to standardize grammatical correctness acceptance levels. Another concern with a test constructed in this fashion is that the scales may not be precise enough to discriminate between one proficiency, competence, level and the next (Clark 1979, po. 42-43). A further question related to the test design is that the communication situations required a response which placed the subjects in the position of taking a role. It may be that a subject does not understand or feel comfortable about this kind of testing 
procedure and the responses could be adversely affected. In addition, the significant issue of appropriate nonverbal communication, that is perceived visually, as it related to speaking delivery is not addressed. There is also the technical concern for tape quality. For both subjects and raters, it is essential that the aural signal be unquestionably clear so that responses and ratings are made on the basis of what is intended to be comprehended. The final reliability question of the test concerns the use of the same person as both an interviewer and voice on the taped test. Although this person was accompanied by a co-investigator for both the interview and test taping, the familiarity of the subjects with that voice may affect the reliability of the subjects' responses and thus the validity of the research.

There may also be questions concerning the sample. In the first place, the final test subjects were not a true random sample, or representative sample of the ESL students at Portland State University. There was an effort to have students from every instructional level and from different language backgrounds included in the study, but it is conceivable that the subjects who participated in this research do not reflect the usual performance of ESL students on such tests.

Secondly, the size of the final sample (25) was not large enough to consider determining the standard error 
of measurement for the experimental taped test. The sample size (20) may also have affected the establishment of validity for the taped test through measuring the degree of association between the taped test and the CELT of listening comprehension. 


\section{CHAPTER V}

\section{IMPLICATIONS FOR ENGLISH AS A SECOND LANGUAGE}

\section{USE OF THE TAPED TEST IN AN ESL PROGRAM}

Placement of Students in

\section{an ESL Program}

The test developed through this research was designed to provide a means of determining a student's oral communicative competence based on the criteria of intelligibility, grammatical correctness, and appropriateness. The results of the test ratings show that there is a significant chance that this test can be used as a valid measure of a student's overall oral competence. United with available standardized scores for the other skills of reading, writing, and listening comprehension, this oral taped test can help provide a more complete picture of the student's Iinguistic and communicative strengths and weaknesses. These data can then be utilized to place a student at the proper level within an instruction program. The taped test would also furnish a permanent record of the student's oral performance at an appointed date which could then be compared with similar tests from an earlier or later date to assess oral competence improvement. However, since the small sample that underwent this research testing 
displayed only three distinct levels from the four ESI placement levels represented by the sample, further implementation of the test with a larger sample is needed to explore this issue of student placement partially on the basis of an oral speaking test.

\section{Practical Implications}

In terms of the practicality of this experimental oral taped test, the primary issues are administration and rating. Since the test is completely on tape, it must be administered via a tape recorder, though this normally does not present a problem for ESI programs. In a language laboratory, it would be possible to administer the test to subjects sitting at every working console at one time, if group testing is preferred, or on a staggered schedule for flexibility. As mentioned earlier, the test is short in length and requires no extra accessories outside of the tape recorder. Importantly, it does not necessitate the presence of trained administrators at the time of administration, although a person familiar with recording equipment is necessary.

Concerning the practicality of the rating procedures, the ratings were generally high for intra-rater and interrater reliability. This indicates that the same ratings are likely to be repeatable at another time. Since each subject's tape segment that is rated is about 5 minutes long, and the rating can be performed during the playing 
of the tape, the time necessary to rate each subject is also approximately 5 minutes. Another advantage of this kind of testing is that once the subject has taken the oral taped test, it can be rated according to the availability and convenience of personnel, preferrably ESI teachers. It is probabile that one or two raters could rate for all three criteria at a moderate level of significance which would decrease the number of raters needed to carry out the rating procedure. It may be necessary, though, to establish a training session to more effectively standardize the rating results.

\section{Diamostic Implications}

The taped test was not specifically designed to be a diagnostic tool; however, the potential for this use exists. of the three criteria intelligibility displays the most likelihood for implementation in this way. The components inhibiting intelligibility (see Appendix A) that are to be marked on the rating sheet by the raters at the end of the rating session would be a valuable reference for the pronunciation teacher, for one, to have available when preparing lessons targeting particular components for improvement. The other criteria of appropriateness and grammatical correctness can primarily illustrate in a general way the level of the subject's ability to use correct grammar while speaking, and behave (orally) appropriately in social situations. 
One final note on implementing this test in an ESI program. While the main object of an ESL curriculum is usually not to specifically "teach for the test" there can be little doubt that students are cognizant of the importance of knowing what is required to pass an examination, especially if it is necessary to obtain a certain score to either be placed in a higher level or to gain entrance into the regular university curriculum. There is thus good reason for students to apply themselves on those subjects for which standardized placement tests are given. It is perhaps possible that, by adding a speaking test to the battery of placement tests, the motivation for the students to direct more attention to their oral communicative ability will increase. Likewise a more competent foreign student is likely to be more successful and be perceived as more successful communicating in academic interactions.

\section{IMPLICATIONS FOR TEACHING ENGLISH}

AS A SECOND LANGUAGE

The development of this test is clearly related to the surging interest in communicative competence evident in the teaching of ESL. There have been numerous texts and articles published whose aim is to help nurture the communicative competence of second language students. Just as there is no fixed definition of communicative competence as yet, there is no set curriculum for developing communicative 
competence in ESL students. The ensuing remarks are not intended to be comprehensive, therefore, but are meant to point out a few of the directions that communicative competence teaching is taking.

One of the best known syllabuses designed to develop communicative competence is called the "notional/functional" syllabus, mentioned in a previous chapter. A number of scholars have gone to a considerable amount of work to define, discuss, and refine this syllabus (see for example, Munby 1981; Johnson 1982; Findley and Nathan 1980; and Wilkins 1976). The opportunity for further discussion of the notional/functional syllabus and communicative syllabuses in general is not over as the recent collection of papers by Johnson (1982) and the review by Ross (1981) indicate. It is not the purpose here to dwell on the notional/functional approach except to briefly remark that it has given the ESI field a way of teaching communicative competence through its emphasis on first assessing a student's communicative needs in terms of notions and functions rather than on grammatical structures. In a competency based program, for example (Findley and Nathan 1980), after the needs of a student have been determined, specific behavioral objectives are identified, and teaching strategies, which can include a wide range of techniques, are implemented. The final segment of the competency based curriculum is evaluation which is directly related 
to the performance of the behavioral objectives. An example of this kind of curriculum in use can be found at Portland Community College. For each instructional level, competencies are explicitly given for such needs as health emergencies, housing, shopping, and banking (1981). It should be, explained that these needs are aimed at the Indochinese refugee population composing the great part of the ESI student body at PCC.

In an already existing curriculum which separates the different language skills into distinct classes, the methods that can help a student become communicatively competent in speaking often have a more explicitly soeiolinguistic emphasis. Take, for example, the Developing Communicative Competence (University of Pittsburgh 1975) series that has been used at the Center for English as a Second Language at Fortland State University. The series has provided appropriate phrases for social interactions and role-play situations that are likely to confront the foreign student in the United States. The interactions also give examples of different formality levels, while leading the student from structured to unstructured opportunities to use the language associated with a particular situation. The role-plays, meant to be used by more advanced students, only provide the situation, roles, and useful expressions. Freed (1978) has suggested that students become involved in actual sociolinguistic 
fieldwork to collect natural samples of speaking in order to develop an awareness of language style differences. Jacobson (1976) and Taylor and Wolfson (1978) offer ways to involve the relationship between roles, social situations, speaking tone, and modes in communication drills. There are also teaching methods which formally address the link between culture and communicative competence. McLeod (1976) discusses the idea of incorporating the learning of culture in the ESI classroom. It is suggested that students and teachers be "viewed as partners in cultural research" ( $p .213$ ), rather than as giver and receivers of knowledge. Both Lafayette (1978) and Seelye (1974) provide credence and methodology for this notion of teaching culture and language together. Although these authors write from a foreign language perspective their ideas could properly be transposed for ESL instruction. Fantini (1977) suggests, in broad terms, a Process Approach that identifies six steps to competence. The last step is that a language learner must "learn the total system of interactional strategies operative in a foreign setting" as well as the language itself to truly be communicatively com- . petent in that setting.

Before going to the concluding statements of this study, a mention should be made of an area related to communicative competence teaching and testing. That is classroom testing of functional language ability. For teachers 
who are searching for a way to evaluate the communicative activities that are used for communicative competence instruction in the classroom, Cohen (1980) is most helpful. He describes three integrative tests that are meant to assess this functional ability, namely the cloze test, dictation; and dialog. Only the last holds an interest for this research as it is the one which calls for actual speech. Similar to research mentioned earlier, Levenston (1975) in particular, this classroom test requests two ESL students, or one student and a native speaker, to construct and perform a dialog from a given situation. The student speaker (or speakers) is then rated on a scale basically taken from Levenston's (1975) which assesses both the form and content of appropriateness. Cohen (1980) divides form into naturalness of discourse, style of expression, and clarity of expression. Content is separated into suitability, accuracy of information, and amount of information related (p. 120). All of these scales use a 5-point Likert-type format. Significantly, Cohen advises teachers to exclude grammaticality at first reasoning that it can be added after the other scales have been rated (p. 123). In practice this scale could be used to assess students' communicative competence in social interactions and roleplays acted out in the classroom. 
CHAPTER VI

SUGGESTIONS FOR FURTHER RESEARCH AND

CONCLUDING REMARKS

SUGGESTIONS FOR FURTHER RESEARCH

The opportunities for further research on communicative competence are numerous. Looking at what the testing research and literature review have revealed, there seem to be two main directions that could be pursued. The first direction for continued research would be to refine the speaking test developed in this study. Several steps could be taken to strengthen the existing validity and reliability of the test. Specifically, for purposes of evaluating the test's validity, it would first be requisite to increase the size of the test sample. Testing all of the students attending the ESL program during a term would be the most ideal circumstance. A larger number of standardized test scores would be available to compare with the oral test. An appropriate test for validity would be to measure the degree of association between the taped test and the recently developed TOEFL Speaking Test. Again, to assess the validity of the taped test, it would be incumbent then to interview the same students that take the oral taped test, employing interviewers not otherwise associated 
with the testing process. In addition to a reliability study of the raters, it might be useful to measure the reliability of the subjects over two separate interviews. Furthermore, it might be beneficial to ask the subjects to perform precisely the same kinds of tasks for both the interview, and the taped test. In other words, such functions as greeting, leave taking, describing an object, and introducing would be explicitly included and rated in both the interview and taped test.

Another possibility for oral testing would be to use a videotape rather than a soundtrack tape. This would open up the opportunity for considering the nonverbal behavioral aspects of communicative competence, as well as the oral and paralinguistic features. As Wiemann (1977) has shown, this is a satisfactory method for exploring communicative competence.

The second direction for research to take would be to incorporate the communicative competence dimensions from the communication perspective into ESL teaching and testing. The behavioral dimensions discussed in the literature, such as empathy, interaction management, and behavioral flexibility need to be analyzed and focused on for their applicability to the ESL curriculum. For example, continuing exploration of the crucial component of empathy already begun by communication and intercultural communication scholars (Bochner and Kelly 1974; 
Wiemann and Backlund 1980; Hwang, Chase, and Kelly 1980; and Szalay 1981) may help to uncover additional behaviors that can be taught to second language learners that will make them more aware of the meaning of the communication behaviors they perceive and better able to respond appropriately to them. In terms of the communicative competence dimension of interaction management, Schneider and Jordan (1981) posed the question: "to what extent is conversational control (interaction management) independent of cultural and linguistic differences?" (p. 187). In this same study of cross cultural perceptions of communicative performance the authors also wondered in general terms "what behaviors function as specific cues to individual person perception" (Schneider and Jordan 1981, p. 188). They suggest that the ability to isolate and analyze these cues would strengthen ESI training. Perhaps the paradigm of Frentz and Farrell (1976), discussed earlier, would provide a concrete starting point for this intercultural research. The above recommendations are merely starting points for investigation. Canale and Swain (1979, pp. 73-77) also indicate a number of possible areas of continued research in communicative competence teaching and testing. 
This study has attempted to meet two challenges. The first and major purpose of the research was to develop, implement, and analyze a test of oral communicative competence for college level ESI students. While the test in its present form will require revision, the research process helped to provide answers to some questions posed about such tests and furnish the basis for new avenues of investigation.

The second, but no less important, purpose of this research was to broaden the background perspective on communicative competence to encompass the work from communication, discourse, and sociolinguistic scholars on this concept. In order to fully develop the potential for applying communicative competence to the areas of teaching and testing, more needs to be known about the dimensions of this competence. This can best be realized through a mutual exchange of information across disciplines. It is hoped that this research will, in some way, be a positive step toward that goal. 


\section{A SELECTED BIBLIOGRAPHY}

Anthony, Edward M. and Norris, William E. "Method in Language Teaching." In Readings on English as a Second Language for Teachers and Teacher-Trainees, pp. 39-42. Edited by Kenneth Croft. Cambridge: Winthrop Pub., 1972.

Argyle, M. Social Interaction. Chicago: Aldine Atherton, 1969.

Bacon, Walter and Ojanen, Sirkka-Liisa. "Foreign Language Conversation Testing at Tampere Language Institute." In Special Is sue on Teaching and Testing Communicative Competence, pp. 55-60. Edited by Voljo Kohonen and Liisa Nummenmaa. Jyvaskyla, Finland: Jyvaskyla University Language Center, 1976.

Baker, William J. "An 'Information-structure' View of Language," The Canadian Journal of Linguistics, 21 (1977), $1-16$.

Bama, LaRay M. "Stumbling Blocks to Intercultural Communication." In Intercultural Communication: A Reader, pp. 241-245. Edited by Larry A. Samovar and R. E. Porter. Belmont: Wadsworth Publishing Co., Inc., 1972.

Bauman, Richard. "Linguistics, Anthropology, and Verbal Art: Toward a Unified Perspective, with a Special Discussion of Children's Folklore." In Georgetown University Round Table on Languages and Linguistics 1927: Linguistics and Anthropology, pp. 13-36. Edited by Muriel SavilleTroike. Wash., D.C.: Georgetown University Press, 1977.

Binham, Philip. "Spoken English Grading Test." In Special Issue on Teaching and Testing Communicative Competence, pp. 61-68. Edited by Voljo Kohonen and Liisa Nummenmaa. Jyvaskyla, Finland: Jyvaskyla University Language Center, 1976.

Bochner, A. P. and Kelly, C. W. "Interpersonal Competence: Rationale, Philosophy, and Implementation of a Con-. ceptual Framework, "Speech Teacher, 23 (1974), 279-301.

Book, Cassandra et al. Human Communication: Principles, Contexts and Ski11s. New York: St. Martin's Press, 1980.

Briere, Eugene J. "Communicative Competence, Variable Rules and Interdisciplinary Research." In Research in Second Language Acquisition: Selected Papers of the Los Angeles Second Language Acquisition Research Forum, pp. 89-94. Edited by Robin C. Scarcella and Stephen D. Krashen. Rowley, Mass.: Newbury House Publishers, Inc., 1980. 
Brown, Gillian. "Understanding Spoken Language," TESOL Quarterly, 12, 3 (1978), 271-283.

Callaway, Donn R. "Accent and the Evaluation of ESL Oral Proficiency." In Research in Language Testing, pp. 102-115. Edited by John W. Oller, Jr. and Kyle Perkins. Rowley, Mass.: Newbury House Publishers, Inc., 1980.

Canale, Michael and Swain, N. Communicative Approaches to Second Language Teaching and Testing. ERIC ED 187 152, 1979.

Carrell, Patricia I. and Konneker, Beverly H. "Politeness: Comparing Native and Nonnative Judgments," Language Learning, 31,1 (1981), 17-30.

Chomsky, Noam. Language and Mind. New York: Harcourt, Brace, Jovanovich, 1972 .

Chreist, Fred M. Foreign Accent. Englewood Cliffs: Prentice-Hall, Inc., 1964.

Clark, John I. D. "Psychometric Considerations in Language "Testing." In Papers in Applied Linguistics Advances in Lanquage Testing Series 2: Approaches to Language Testing, pp. 15-30. Edited by Bernard Spolsky. Arlington, VA: CAI, 1978.

"Direct vs Semi-Direct Tests of Speaking Ability." In Concepts in Language Testing: Some Recent Studies, pp. 35-49. Edited by Eugene J. Briere and Frances Butler Hinofotis. Wash., D.C.: TESOL, 1979.

Cohen, Andrew D. Testing Language Ability in the Classroom. Rowley, Mass.: Newbury House Publishers, Inc., 1980. and Elite Olshtain. "Developing a Measure of Sociocultural Competence: The Case of Apology," Language Learning, 31, 1 (1981), 113-134.

Ervin-Tripp, Susan. "Children's Sociolinguistic Competence and Dialect Diversity." In Sociolinguistic Aspects of Language Learning and Teaching, pp. 27-4l. Edited by J. B. Pride. Oxford: Oxford University Press, 1979.

Esler, Megan et al. English as a Second Language Curriculum: Survival and Prevocational Competencies. Portland, OR: Portland Community College, 1981.

Fantini, Alvino E. "Focus on Process: An Examination of the Learning and Teaching of Communicative Competence." In Beyond Fxperience: The Experiential Approach to CrossCultural Education, pp. 47-53. Edited by Donald Batchelder and Elizabeth G. Warner. Brattleboro: The Experiment in International Living, 1977. 
Findley, Charles A. and Nathan, Lynn A. "Functional Language Objectives in a Competency Based ESL Curriculum," TESOL Quarterly, 14, 2 (1980), 221-231.

Fisher, Hilda. Improving Voice and Articulation. 2nd ed. Boston: Houghton Mifflin Company, 1975.

Fishman, Joshua. Sociolinguistics: A Brief Introduction. Rowley, Mass.: Newbury House Publishers, Inc., 1972.

Folland, David. "Group Conversation as a Means of Teaching and Testing Spoken Language." In Special Issue on Teaching and Testing Communicative Competence, pp. 6168. Edited by Voljo Kohonen and Liisa Nummenmaa. Jyvaskyla, Finland: Jyvaskyla University Language Center, 1976.

Freed, Barbara F. Language in Education: Theory and Practice 6. "From the Community to the Classroom:

Gathering Second-Ianguage Speech Samples." Arlington: Center for Applied Linguistics, 1978.

Frentz, Thomas $S$. and Farrell, Thomas B. "Language-action: A Paradigm for Communication," Quarterly Journal of Speech, 62, 2, 333-349.

Garfinkel, H. Studies in Ethnomethodology. Englewood Cliffs: Prentice-Hall, 1968.

Goffman, Erving. The Presentation of Self in Everyday Life. Garden City, NY: Doubleday Anchor, 1959.

"On Face-Work: An Analysis of Ritual Elements in Social Interaction. " In Language, Culture and Society: A Book of Readings," pp. 224-249. Edited by Ben Blount. Cambridge: Winthrop Publishers, Inc., 1974.

Gordon, Morton J. Speech Improvement. Englewood Cliffs: Prentice-Hall, 1968.

Gumperz, John J. "Forward." In Sociocultural Dimensions of Language Use. Edited by Mary Sanches and Ben G. Blount. New York: Academic Press, 1975.

"Sociocultural Knowledge in Conversational Infërence." In Georgetown University Round Table on Languages and Linguistics 1972: Linguistics and Anthropology, pp. 191-2ll. Edited by Muriel Saville-Troike. Wash., D.C.: Georgetown University Press, 1977.

Hendricks, Debby et al. "Oral Proficiency Testing in an Intensive English Language Program." In Research in Languase Testing, pp. 77-90. Edited by John W. Oller, Jr. and Kyle Perkins. Rowley, Mass.: Newbury House Publishers, Inc., 1980. 
Hinofotis, F. B. "An Investigation of the Concurrent Validity of Cloze Testing as a Measure of Overall Proficiency in English as a Second Language."

Ph.D. dissertation, Southern Illinois University. Cited by John I. Clark, "Direct vs Semi-Direct Tests of Speaking Ability." In Concepts in Language Testing: Some Recent Studies. Edited by Eugene J. Briere and Frances Butler Hinofotis. Wash., D.C.: TESOL, 1979.

Hwang, John, Chase, Lawrence J., and Kelly, Clifford W. "An Intercultural Examination of Communication Competence," Communication, 9, 2 (1980), 70-79.

Hymes, Dell. "The Ethnography of Speaking." In Language, Culture and Society, pp. 189-223. Compiled by Ben G. Blount. Cambridge: Winthrop Publishers, Inc., 1974.

"Models of the Interaction of Language and Social Setting," The Journal of Social Issues, 23, 2 (1967), $8-28$.

"On Communicative Competence." In Sociolinguistics: Selected Readings, pp. 269-293. Edited by J. B. Pride and J. Holmes. Harmondsworth: Penguin Books, Ltd., 1972.

Jacobson, Rodolfo. "Incorporating Sociolinguistic Norms into an EFI Program," TESOL Quarterly, 10, 4 (1976), $411-422$.

Jakobovits, Leon A. and Gordon, Barbara. The Context of Foreign Language Teaching. Rowley, Mass.: Newbury House Publishers, Inc., 1974.

Johnson, Keith. Communicative Syllabus Design and Methodology. Oxford: Pergamon Press, 1982.

Jones, Randall I. "The Oral Interview of the Foreign Service Institute." In Papers in Apolied Iinguistics: Advances in Language Testing Series: 1: Some Major Tests, pp. 104-1.13. Edited by Bermard Spolsky. Arlington: Center for Applied Linguistics, 1979.

Jurick, Donna M. "The Enactment of Returning: A Naturalistic Study of Talk," Communication Quarterly, 25, 3 (1977), $21-29$.

Kettering, Judith Carl. Developing Communicative Competence: Interaction Activities in English as a Second Ianguage. Pittsburgh: University of Pittsburgh, 1975. 
Kim, Young Yun. "Communication Patterns of Foreign Immigrants in the Process of Acculturation," Human Communication Research, 4, 1 (1977), 66-67.

Lafayette, Robert C. "Teaching Culture: Strategies and Techniques." In Language in Education: Theory and Practice. Arlington: Center for Applied Iinguistics, 1978.

Leutenegger, Ralph R. The Sounds of American English: An Introduction to Phonetics. Glenview: Scott, Foresman and Company, 1963.

Levenston, E. A. "Aspects of Testing the Oral Proficiency of Adult Immigrants to Canada." In Papers on Language Testing 1967-1974, pp. 67-74. Edited by Leslie Palmer and Bernard Spolsky. Wash., D.C.: TESOL, 1975.

Iittlewood, William. Communicative Language Teaching: An Introduction. Cambridge: University Press, 1981.

Litton-Hawes, Elaine M. "A Eoundation for the Study of Everyday Talk," Communication Quarterly, 25, 3 (1977), $2-11$.

McLeod, Beverly. "The Relevance of Anthropology to Language Teaching," TESOI Quarterly, 10, 2 (1976), 211-220.

Morley, Joan. Improving Spoken English: An Intensive Personalized Program in Perception, Pronunciation, Practice in Context. Ann Arbor: University of Michigan Press, 1979.

Morrow, K. "Communicative Language Testing: Revolution or Evolution?" In The Communicative Approach to Language Teaching. Edited by C. Brumfit and K. Johnson. Oxford: Oxford University Press, 1979.

Mullen, Karen. "A Direct Evaluation of Second Language Proficiency: The Effect of Rater and Scale in Oral Interviews," Language Learning, 28, 2 (1978), 301.

"Rater Reliability and Oral Proficiency Evaluations." In Research in Language Testing, pp. 91-101. Edited by John W. Oller, Jr. and Kyle Perkins. Rowley, Mass.: Newbury House Publishers, Inc., 1980.

Munby, John. Communicative Syllabus Design: A Sociolinguistic Model for Defining the Content of PurposeSpecific Language Programmes. Cambridge: Cambridge University Press, 1981.

Nicholson, Paul. "Improving Interview Tests," TESOL Newsletter, 15, I, pp. 25, 28. 
Nofsinger, Robert E. Jr. "A Peek at Conversational Analysis," Communication Quarterly, 25, 3 (1977), 12-20.

Oller, John W. Jr. "Communicative Competence: Can It Be Tested?" In Research in Second Language Acquisition: Selected Papers of the Los Angeles Second Language Acquisition Research Forum, pp. 95-104. Edited by Robin C. Scarcella and Stephen D. Krashen. Rowley, Mass.: Newbury House Publishers, Inc., 1980.

Paulston, Christina Bratt. "Linguistic and Communicative Competence," TESOL Quarter1y, 8, 4 (1974); 347-362.

"Developing Communicative Competence: Goals, Procedures, and Techniques." In The Human Factors in ESI, pp. 20-39. Edited by James E. Alatis and Ruth Crymes. Wash., D.C.: TESOL, 1977.

et al. Developing Communicative Competence: Roleplays in English as a Second Languagre. Pittsburgh: University of Pittsburgh, 1975.

Prator, Clifford H. Jr., and Robinett, Betty Wallace. Manual of American English Pronunciation. 3rd ed. New York: Holt, Rinehart and Winston, Inc., 1972.

"Progress Report of TEOFL Speaking Test Study and Discussion of Next Steps." Princeton: TOEFI, 1978.

Ross, David. "From Theory to Practice: Some Critical Comments on the Communicative Approach to Language Teaching," review in Language Leaming, 31, 1 (1981), $223-242$.

Sanders, R. E. "The Constraints of Symbol Systems." Paper presented at the Speech Communication Association annual conference, San Antonio, Texas, 1979. (In Schneider, 1980.)

Savignon, Sandra J. Communicative Competence: An Experiment in Foreign Language Teaching. Philadelphia: The Center for Curriculum Development, Inc., 1972.

Schneider, Michael J. "Verbal and Nonverbal Indices of the Communicative Performance and Acculturation of Chinese Immigrants." Paper presented at the Society For Intercultural Education, Training and Research (SIETAR) Annual Conference, March, 1980, Mt. Pocono, Pennsylvania.

and Jordan, William. "Perception of the Communicative Performance of Americans and Chinese in Intercultural Dyads," IJIR, 5, 2 (1981), 175-191. 
Scholz, George et al. "Is Language Ability Divisible or Unitary? A Factor Analysis of 22 English Language Proficiency Tests." In Research in Language Testing, pp. 24-33. Edited by John W. Oller, Jr. and Kyle Perkins. Rowley, Mass.: Newbury House Publishers, Inc., 1980.

Schutz, Noel W. Jr., and Derwing, Bruce I. "A Theoretical Defense of the Pattern Driil." In 1967-77 Papers in ESI: Selected Conference Papers of the Association of Teachers of English as a Second Language, pp. 1724. Edited by Betty Wallace Robinett. Wash., D.C.: NAFSA, 1977.

Searle, John R. Speech Acts: An Essay in the Philosophy of Language. Cambridge: Cambridge University Press, 1969.

"Indirect Speech Acts." In Syntax and Semantics. Voi. 3: Speech Acts. Edited by P. Cole and J. Morgan. New York: Academic Press, 1975.

Seelye, H. Ned. Teaching Culture: Strategies for Foreign Language Educators. Skokie: National Textbook Co., 1974.

Sinclair, J. et al. "The English Used by Teachers and Pupils: Final Report to SSRC." Birmingham, England: Dept. of English Language and Iiterature, Birmingham University, 1972.

Smith, Larry E. and Rafiqzad, Khalilullah. "English for Cross-Cultural Communication: The question of Intelligibility," TESOL Quarterly, 13, 3 (1979), 371-380.

Spolsky, Bernard, Murphy, Penny, Holm, Wayne, and Ferrel, Allen. "Three Functional Tests of Oral Proficiency." In Papers on Languase Testing 1967-1974, pp. 75-90. Edited by Leslie Palmer and Bernard Spolsky. Wash., D.C.: TESOI, 1975.

Szalay, Lorand B. "Intercultural Communication: A Process Model," IJIR, 5, 2 (1981), 133-146.

Taylor, Barry P. and Wolfson, Nessa. "Breaking Down the Free Conversation Myth," TESOL Quarterly, 12, 1 (1978), 31-39.

Technical Institute for the Deaf Speech Intelligibility Rating Scale. In Geffner, Donna S. et al. "Speech and Language Assessment Scales of Deaf Children," Journal of Communication Disorders, 11,2 (1978), $215-226$. 
Toulmin, Stephen. "Concepts and the Explanation of Behavior." In Human Action, pp. 71-104. Edited by Theodore Mischel. New York: Academic Press, 1969.

Watzlawick, Paul, Beavin, Janet Helmick, and Jackson,

Don D. Pragmatics of Human Communication. New York:

W. W. Norton Co., Inc., 1967.

Widdowson, H. A. "The Teaching of Rhetoric to Students of Science and Technology." In Science and Technology in a Second Language. Centre for Information in Language Teaching and Research, 1971.

"EST in Theory and Practice." In English for Academic Study. British Council English Teaching Information Centre, 1975.

Wiemann, John M. "Explication and Test of a Model of Communicative Competence," Human Communication Research, 3,3 (1977), 195-213.

and Backlund, Philip. "Current Theory and Research in Communicative Competence," Review of Educational Research, 50, I (1980), 185-199.

Wilds, Claudia P. "The Oral Interview Test." In Testing Language Proficiency, pp. 29-38. Edited by Randali L. Jones and Bernard Spolsky. Arlington: Center for Applied Iinguistics, 1975.

Wilkins, David. Notional Syllabuses. Oxford: Oxford University Press, 1976.

Williams, Frederick. Reasoning with Statistics: Simplified Examples in Communication Research. New York: Holt, Rinehart and Winston, Inc., 1968.

Yorozuya, Ryuichi and Oller, John W. Jr. "Oral Proficiency Scales: Construct Validity and the Halo Effect," Language Learning, 30, I (1980), 135-154. 
APPENDIX A

NOTE TO INTEIIIGIBIIITY RATERS AND

RATING SHEET FOR INTEIIIGIBILITY 
NOTE TO INTELIIGIBILITY RATERS

1. Rate each total student response to the communication situations (10) on the following scale:

I - Speech cannot be understood

2 - Speech is very difficult to understand with only isolated words or phrases intelligible.

3 - Speech is difficult to understand; however, the gist of the content can be understood. Two-tothree word utterances are intelligible.

4. - Speech is intelligible with the exception of a few words or phrases.

5 - Speech is completely intelligible.

The basic criterion for this rating is ease of understanding the student's oral production. Some oral production components which may affect intelligibility are:

Voice Quality - if excessively breathy, harsh, or nasal.

Loudness - if too loud or too weak.

Rate - if too fast, slow, or jerky.

Pronunciation - if vowel or consonant choice is incorrect.

Stress (intensity, duration, and pitch)

Syllable stress - if misplaced

Phrasing - if pauses dividing thought groups are unrelated to meaning

Rhythm - if the strong/weak stress contrasts are inadequate

Intonation - if the pitch level contrasts of the response do not form meaningful contours

2. At the end of the tape rating, please mark the oral production components you think inhibited your understanding of the student's responses. 
RATING SHEET FOR INTELLIGIBILITY

(Used for both Interview and Taped Tests)

Student

Rater

Date

Communication Situations: (Circle or otherwise indicate the appropriate rating)

$\begin{array}{lll}\text { Cannot be understood } & \text { Completely } \\ \text { inteligible Response }\end{array}$

1.

\begin{tabular}{lllll}
1 & 2 & 3 & 4 & 5 \\
\hline 1 & 2 & 3 & 4 & 5 \\
\hline 1 & 2 & 3 & 4 & 5 \\
\hline 1 & 2 & 3 & 4 & 5 \\
\hline
\end{tabular}

$\mathrm{NR}$

2 .

3 .

4.

\begin{tabular}{lllll}
1 & 2 & 3 & 4 & 5 \\
\hline
\end{tabular}

Pt. 2

\begin{tabular}{lllll}
1 & 2 & 3 & 4 & 5 \\
\hline
\end{tabular}

\begin{tabular}{lllll}
1 & 2 & 3 & 4 & 5 \\
\hline
\end{tabular}

NR

5. Pt. 1

6. Pt. I

34

5

$\mathrm{NR}$

NR

Pt. 2

3

5

NR

7. Pt. I

1

3

5

NR

Pt. 2

2

3

5

$\mathrm{NR}$

Components Inhibiting Intelligibility: (Mark all appropriate)

Voice Quality
Loudness
Rate
Pronunciation
Syllable Stress Phrasing Rhythm Intonation

Note: Possible Point Range: 10 - 50 
APPENDIX B

NOTE TO GRAMMATICAL CORRECTNESS RATERS AND RATING SHEET FOR GRAYMATICAL CORRECTNESS 


\section{NOTE TO GRAMMATICAL CORRECTNESS RATERS}

Rate the student responses for the Speaking Test on a Yes/No scale for each item of Part 2--Situations to Respond to. Do not rate Part 1--Short Questions and Answers. The Yes rating should be given when the response is completely correct in terms of standard American English grammar used in oral production. The № rating should be given when the response is not correct according to standard American English syntax. No rating is given when there is no response, but the lack of response is noted. The final judgment for the rating is your determination of the response as grammatically correct. Allowance should be made for self-corrections. 
RATTNG SHEEI FOR GRAMMATICAI CORRECTNESS

Student

Rater

Date

Communication Situations: (Mark Yes or No, or No Response, as appropriate)

1 .

2 .

3 .

4.

5. Pt. I

Pt. 2

6. Pt. I

Pt. 2

7. Pt. I

Pt. 2

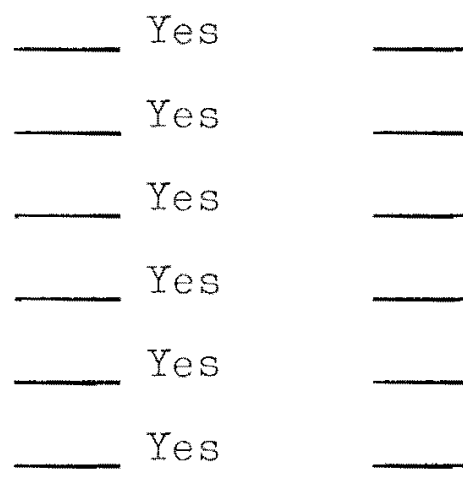

Yes

Yes

Yes

Yes
No

No

No

No

No

No

No

No

No

No
No Response No Response No Response No Response No Response No Response No Response No Response No Response No Response

Yes $=1$

No and No Response $=0$

Possible Point Range: $0-10$ 
APPENDIX C

THE ORAI TNTERVIEW OF THE FOREIGN SERVICE INSTITUTE, PERFORMANCE FACTORS, AND RATING SCALE 
THE ORAL INTERVIEW OF THE FOREIGN SERVICE INSTITUTE, PERFORMANCE FACTORS, AND RATING SCATE

\section{ACCENT - Trial Interview Test only}

1. Pronunciation frequently unintelligible.

2. Frequent gross errors and a very heavy accent make understanding difficult, require frequent repetition.

3. "Foreign accent" requires concentrated listening and mispronunciations lead to occasional misunderstanding and apparent errors in grammar or vocabulary.

4. Marked "foreign accent" and occasional mispronunciations which do not interfere with understanding.

5. No conspicuous mispronunciations, but would not be taken for a native speaker.

6. Native pronunciation, with no trace of "foreign accent."

GRAMMAR

1. Grammar almost entirely inaccurate except in stock phrases.

2. Constant errors showing control of very few major patterns and frequently preventing communication.

3. Frequent errors showing some major pattems uncontrolled and causing occasional irritation and misunderstanding.

4. Occasional errors showing imperfect control of some patterns but no weakness that causes misunderstanding.

5. Few errors, with no patterns of failure.

6. No more than two errors during the interview.

\section{VOCABULARY}

1. Vocabulary inadequate for even the simplest conversation.

2. Vocabulary Iimited to basic personal and survival areas (time, food, transportation, family, etc.).

3. Choice of words sometimes inaccurate; limitations of vocabulary prevent discussion of some common professional and social topics.

4. Professional vocabulary adequate to discuss special interests; general vocabulary permits discussion of any nontechnical subject with some circumlocutions.

5. Professional vocabulary broad and precise; general vocabulary adequate to cope with complex practical problems and varied social situations.

6. Vocabulary apparently as accurate and extensive as that of an educated native speaker. 
FUUENCY - Trial Interview Test only

1. Speech is so halting and fragmentary that conversation is virtually impossible.

2. Speech is very slow and uneven except for short or routine sentences.

3. Speech is frequently hesitant and jerky; sentences may be left uncompleted.

4. Speech is occasionally hesitant, with some unevenness caused by rephrasing and groping for words.

5. Speech is effortiess and smooth, but perceptibly nonnative in speed and evenness.

6. Speech on all professional and general topics as effortless and smooth as a native speaker's.

COMPREHENSION

1. Understands too little for the simplest type of conversation.

2. Understands only slow, very simple speech on common social and touristic topics; requires constant repetition and rephrasing.

3. Understands careful, somewhat simplified speech airected to him, with considerable repetition and rephrasing.

4. Understands quite well normal educated speech directed to him, but requires occasional repetition or rephrasing.

5. Understands everything in normal educated conversation except for very colloquial or low-frequency items, or exceptionally rapid or slurred speech.

6. Understands everything in both formal and colloquial speech, to be expected of an educated native speaker.

Note: Only the first 5 rating levels were used for this research. 
APPENDIX D

NOTE TO APPROPRIATENESS RATERS AND

RATING SHEET FOR APPROPRIATENESS 
NOTE TO APPROPRIATENESS RATERS

Rate the student responses for the Speaking Test on a Yes/No scale for each item of Part 2--Situations to Respond to. Do not rate Part 1--Short Questions and Answers. The Yes rating should be given when the response is consistent with your expectation of an acceptable response to the situation. The No rating should be given when the response seems unrelated to or inconsistent with your expectation of an acceptable response to the communication situation context.

This evaluation should include consideration of the words and phrases used, their order of utterance in the total response, and the formality level of the response. Also, the vocal tone of the response should be consistent with the verbal code and with the role of the communicant (student speaker) within the communication situation context. 
RATING SHEET FOR APPROPRIATENESS

Student

Rater

Date

Communication Situations: (Mark Yes or No, or No Response, as appropriate)

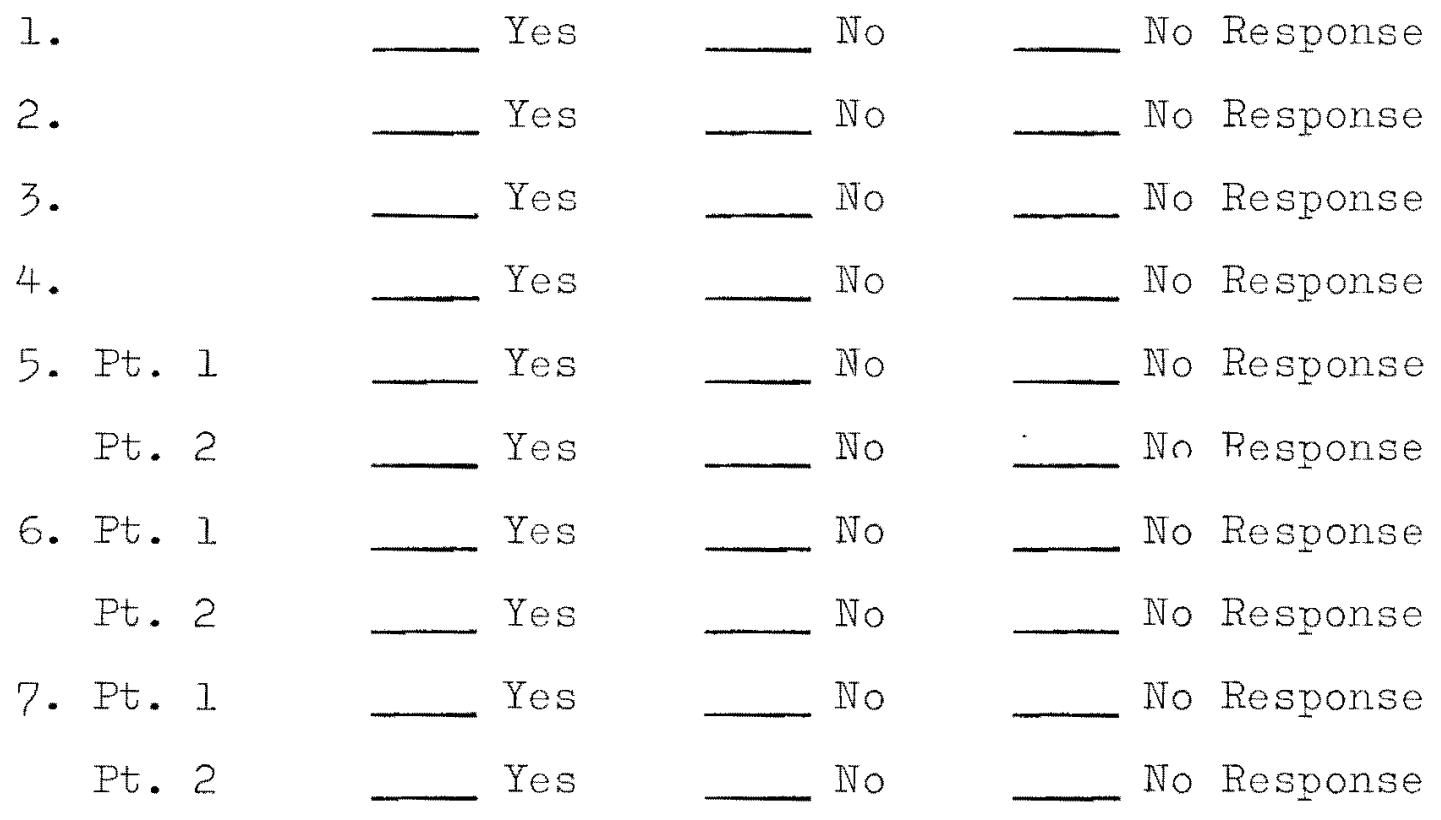

Yes $=1$

No and No Response $=0$

Possible Point Range: 0-10 
APPENDIX E

APPROPRIATENESS RATING SCALE FOR TRIAL AND FINAI INTERVIEW TEST 


\section{APPROPRIATENESS RATING SCALE FOR TRIAL} AND FINAL INTERVIEW TEST

RATING

1

2

3

4

5
DESCRIPTION

Language (verbal and nonverbal) and behavior completely incongruent within the time, place, rights, and obligations of the role relationship framework of the interview.

Language (verbal and nonverbal) and behavior was often not congruent with expected norms of behavior within the context of the interview.

Language (verbal and nonverbal) and behavior was sometimes not congruent within the expected norms of behavior for this context, the interview.

Language (verbal and nonverbal) and behavior was mostly congruent within the expected norms of behavior for this context, the interview.

Language (verbal and nonverbal) and behavior seemed completely congruent within the context of the interview, as if the speaker was a competent native speaker.

\section{CONTEXT FACTORS}

1. Role relationship: student to interviewers (student researcher and teacher trainee.

2. Time: during the school day, usually the noon hour or after classes.

3. Place: Room 310 Shattuck Hall, an ESI classroom.

4. Interaction type: personal, informal, consultative.

5. Channels: verbal and nonverbal language and behavior.

SPECIPTC BEHAVIORS ATTENDED TO

1. Greeting behavior

2. Leave taking behavior 
3. Introductions, response to

4. Body posture, haptics, though constrained by furniture arrangement--sitting at a table

5. Formality level

6. Eye contact 
APPENDIX F

TAPED TEST SCRIPT 


\section{TAPED TEST SCRIPT}

INSTRUCTIONS: (Not rated)

This is a speaking test that will give you an opportunity to show your ability to communicate in English. The test has two parts:

Part I: Short questions and answers

Part II: Situations to Respond to

After each question or situation you will be given a short time to respond. Try to answer immediately and speak normally and clearly so others will understand you.

Part I:

Short questions and answers. These will be given only once so please listen carefully. Answer the following questions. You may use short answers or complete sentences. Here is an example: What room is this? Your answer will be either "96 Neuberger Hall" or "This is room 96 Neuberger Hall."

Questions:

1. What is your name?

2. What is your native country?

3. What is your native language?

4. What is your major field?

5. Are you a graduate or undergraduate student? 
Part II:

Situations to Respond to. In the following situations you will be asked to give the appropriate response or ask the suitable question. Please listen carefully and respond immediately. The situation will be given only once. For example: Today is your friend's birthday. What do you say to him? Your answer will be: "Happy Birthday!" No. 1. You are a new student and you need to buy your textbooks. Ask another student in your class for directions to the bookstore.

No. 2. You had an appointment with your professor at 3:00. You didn't get there until 3:15. What do you say to him?

No. 3. You are talking to an American friend. Suddenly you know that you will be late to your next class. What will you say to your friend?

No. 4. Yesterday you received a library fine notice for an overdue book. However, you know you didn't check the book out. What do you say to the librarian? The following situations each have two parts. Respond to each part as it is given. No. 5, Part 1. You are in the cafeteria looking for a place to sit. You see one person you don't know sitting at a large table. What do you say? 
No. 5, Part 2. After talking a little, how would you introduce yourself?

No. 6, Part 1. You are talking with an apartment manager who does not know the kind of apartment you want. Describe the apartment you are looking for.

No. 6, Part 2. The apartment manager shows you an apartment, but you don't like it, and you want to leave. What do you say?

No. 7, Part 1. You are eating dinner at an American home. You don't like the meat dish, but you eat it. The mother offers you more. What do you say?

No. 7, Part 2. Now you are eating the dessert and you like it very much. What do you say?

Total Taped Test time: 7 minutes

Total Rating time: 5 minutes, approximately. (INSTRUCTIONS removed from rated tapes.) 
APPENDIX G

INTERACTION QUEST IONNAIRE 
INTERACTION QUESTIONNATRE

Name

Country

Language

1. How long have you been in the United States?

_ Less than 3 months

- 3 to 6 months

_ 6 months to I year

1 year to 3 years

- More than 3 years

2. How long have you studied English?

3. Where did you study English before coming to the U.S.?

__ Home country Other English speaking country Did not study English before coming to the U.S.

4. Were your English teachers, before the U.S., American?

- Yes _ No

5. How often do you speak English?

Never
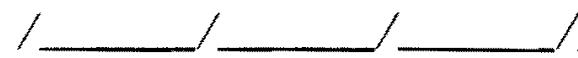

Always 6. Who do you talk to in English? (Mark all appropriate

a. I talk to my American classmates:

Never

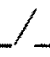

Always

b. I talk to my international (non-U.S.) classmates:

Never
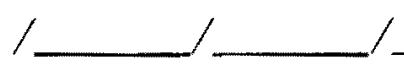

Always

c. I talk to my teachers and professors:

Never

$$
1
$$

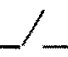

Always 
d. I talk to other Americans I know:

Never

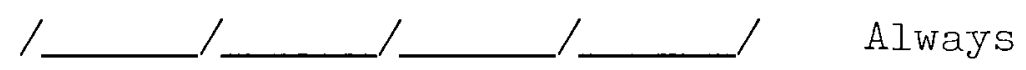

e. I talk to other Americans I do not know: Never

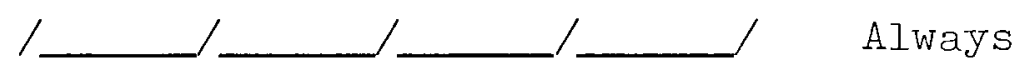

f. I talk to fellow workers:

Never

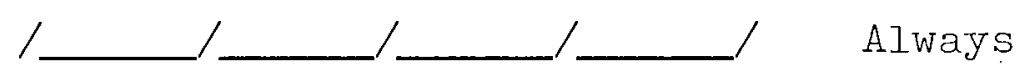

